\title{
EMPOWERING INDIGENOUS MEXICAN GROUPS THROUGH FOSTERING THE PRACTICE OF TRADITIONAL TEXTILE CRAFTS
}

\author{
by \\ Hoshiakari Endo Portillo \\ Hon Bachelor of Textile Design, Universidad Iberoamericana, Mexico, 2002
}

\author{
A Major Research Project \\ presented to Ryerson University \\ in partial fulfillment of the \\ requirements for the degree of \\ Master of Arts in Fashion
}

Toronto, Ontario, Canada, 2018

CHoshiakari Endo Portillo 2018 


\section{AUTHOR'S DECLARATION FOR ELECTRONIC SUBMISSION OF A MRP}

I hereby declare that I am the sole author of this MRP. This is a true copy of the MRP, including any required final revisions.

I authorize Ryerson University to lend this MRP to other institutions or individuals for the purpose of scholarly research.

I further authorize Ryerson University to reproduce this MRP by photocopying or by other means, in total or in part, at the request of other institutions or individuals for the purpose of scholarly research.

I understand that my MRP may be made electronically available to the public. 


\begin{abstract}
In a world in which globalization and technology are at their peak, indigenous Mexican communities are struggling between the pull of modernity and their ancestral traditions. They are caught between two antagonistic practices - the tension between mass-produced and traditional handcrafted textiles. This research explored strategies to foster traditional textile crafts amongst indigenous Mexican communities with the purpose of empowering indigenous Mexican groups. The main outcome of this creative research is a swimwear collection created in collaboration with indigenous Mexicans artisans. Each piece conveys indigenous Mexican craft authentically and through the creation process I was able to outline some guidelines to effectively nurture the practice of traditional textile crafts in Mexico. Given that traditional textile crafts practised by other indigenous communities are striving to survive, the findings of this study provide valuable guiding principles to preserve and reinforce the cultural legacies of traditional textiles crafts.
\end{abstract}




\section{Acknowledgements}

This Major Research Project has been a great accomplishment for me, something I never thought I would realize. Great things are never done alone, and I could not have completed this project without the help and support of many individuals. I would like to extend my sincere thanks to all of them.

I would like to especially thank Henry Navarro and Sandra Tullio-Pow for their guidance and invaluable support; your help was the key to completing this research.

Jean-Francois, thanks for all your support and unconditional love. Juliana and Liam, you are my inspiration. Mom, Dad, Midori, even in the distance, you are close to my heart. Thank you all for sparing some of our time together so I could achieve this project. 


\section{Table of Contents}

\section{Page}

Author's Declaration................................................................................. ii

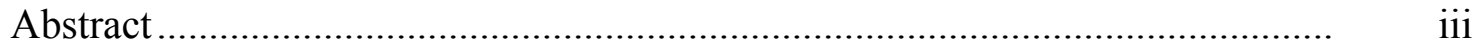

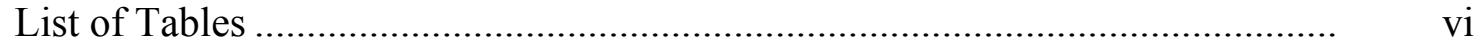

List of Figures .............................................................................. vii

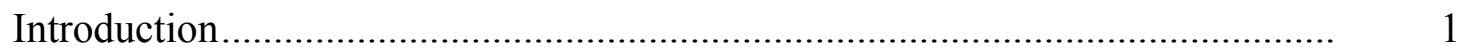

Research Questions ......................................................................... 2

Researcher's Background .................................................................... 3

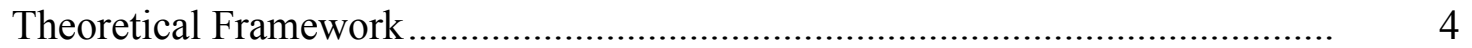

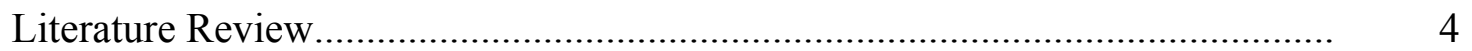

Canastitas en Serie (Series of Little Baskets)....................................... 5

Cultural Empowerment ............................................................................ 6

Legacy and Cultural Appropriation..................................................... 7

Design, Crafts, and Storytelling …...................................................... 9

Ethical Labour and Fair Trade.............................................................. 11

Environmental Awareness and Slow Fashion ...................................... 12

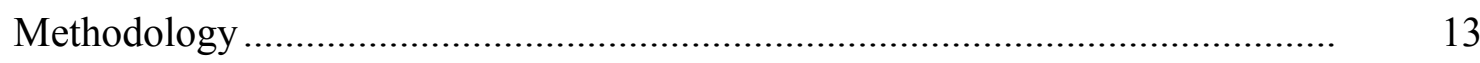

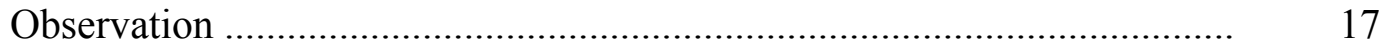

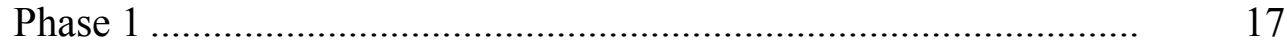

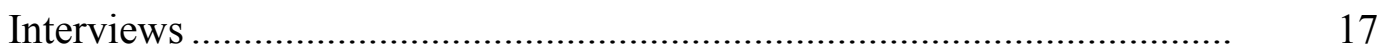

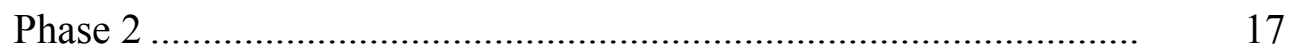

Phase 3 ........................................................................ 18

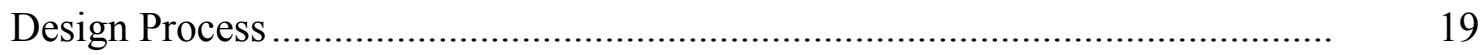

Artisan \#1 ...................................................................................... 21

Swimsuit \#1: Beaded bikini ........................................................... 23

Swimsuit \#2: Bikini embroidered Tenango style........................... 24

Artisan \#2 .................................................................................... 26

Swimsuit \#3: Bikini flower embroidery ....................................... 27

Swimsuit \#4: Black monokini.......................................................... 28

Swimsuit \#5: One-piece suit with scallops .................................. 30

Cover-up "cáscara de tomate" stitch............................................ 31

Editorial Photoshoot ..................................................................... 33

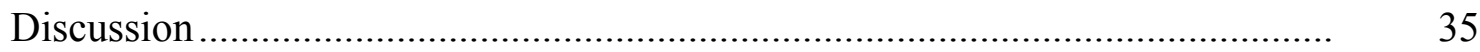

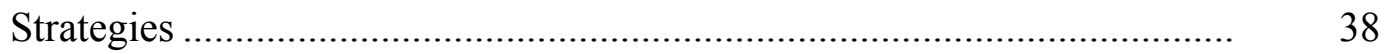

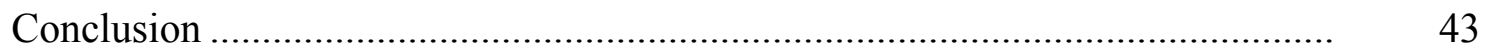

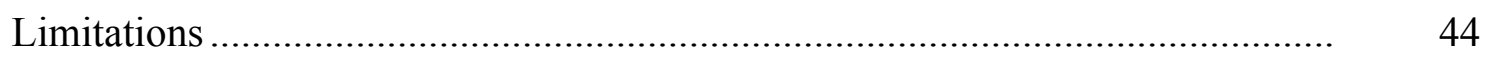

Appendix A: Swimsuits Before Being Embroidered by the Artisans................... 46

Appendix B: Editorial Photoshoot of the Swimwear Collection ......................... 47

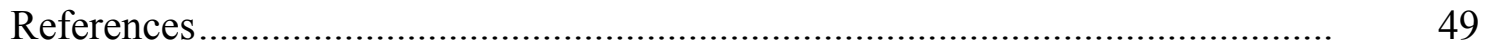




\section{List of Tables}

Table $\quad$ Page

1. Summary of Methods and Guiding Questions ....................................... 15 


\section{List of Figures}

$\begin{array}{lll}\text { Figure } & \text { Page }\end{array}$

1. Methods utilized, divided into four different phases............................... 15

2. Map of Mexico—San Pablito _.............................................................. 20

3. Bikini beaded by Artisan \#1 with a beaded bird motif............................. 23

4. Beaded bikini detail........................................................................ 23

5. Bikini embroidered by Artisan \#1 like a Tenango .................................. 24

6. Embroidered bikini detail .................................................................. 25

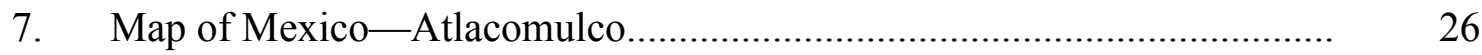

8. Bikini with flowers, embroidered by Artisan \#2 …................................ 27

9. Flower detail embroidered by Artisan \#2 ................................................. 28

10. Monokini embroidered by Artisan \#2 …................................................. 29

11. Detail of monokini embroidery in the trimmings................................... 29

12. One-piece swimsuit embroidered with crocheted scallops, made by Artisan \#2 ........................................................................................ $\quad 30$

13. Detail of one-piece swimsuit embroidery............................................. 31

14. Cover-up made by Artisan \#2 with the stitch "cascara de tomate" ............ 32

15. Cover-up fabric before being embroidered by Artisan \#2 ........................ 32

16. "Cascara de tomate" stitch............................................................... 32

17. Full-shot swimwear collection; bikini with Tenango-style embroidery Artisan \#1 ................................................................................... 34

18. Close-up of bikini embroidered like a Tenango made by Artisan \#2......... 34 


\section{Introduction}

Mexico is a country known for a rich diversity of traditional crafts that are directly linked to its national identity. Ana Paula Fuentes, the director of Oaxaca Textile Museum, explained that "distinct ethnic groups developed the designs, shapes, and colors of their clothing from their own culture, their way of life, their rules and customs, from their rituals, and beliefs" (as cited in Garcia \& Vinebaum, 2016, p. 125). Given that Mexican arts and crafts are imbued with indigenous Mexican history, culture, and identity, it is very important to preserve Mexican artisans' practice. However, the future of traditional Mexican crafts is endangered; it faces threats from the forces of globalization and fast-fashion consumption practices. On top of that, indigenous Mexican communities have been affected negatively by colonization beginning with the Spanish conquistadors in the 16th century until the present day. According to Wilson (2004), colonization processes have been about "civilizing" (p. 360) indigenous groups, which has put the latter's cultural legacy at risk because "Indigenous Peoples were taught the worthlessness of [their] traditions and knowledge; [colonization] was designed to perpetuate the colonial machine" (p. 360). Like other indigenous societies around the world, indigenous Mexican people were obliged to adopt the traditions of their colonists, because it was believed that European traditions were superior.

The aim of this MRP is to determine the factors that support empowerment of indigenous Mexican groups by way of fostering their crafts. The incorporation of their traditional textile practices into products that are marketed in the global fashion marketplace was analyzed in order to measure such products' impact. This could provide indigenous Mexican groups with a source of income and at the same time preserve their cultural traditions. Moreover, the work of participating indigenous craftspeople may be recognized by larger audiences and the value of their efforts fairly remunerated. 
To achieve these goals, I proposed the development of a swimwear line created in collaboration with crafts practitioners from the aforementioned indigenous Mexican groups. The main concept for the proposed swimwear line is to create garments with global appeal that are imbued with indigenous stories and traditions from Mexico. The stories and traditions embedded in the garments are meant to generate a stronger connection with the wearer. Therefore, people who purchase such garments may keep those items for a longer time. To educate the consumers about these practices when buying crafts, they will be informed of the benefits their purchases will bring to the indigenous groups who made them.

In developing the idea of creating garments that integrate indigenous Mexican textile craft traditions, my first thought was to make swimwear garments. This was primarily because of my experience working in the swimwear industry. Therefore, I decided that a swimwear collection would fit perfectly with my goals for the study. My experience regarding swimwear trends, forms, and shapes combined with Mexican textile crafts resulted in very interesting and appealing designs because each of the individual items is imbued with meaningful elements of indigenous Mexican textile crafts.

\section{Research Questions}

Because the main objective of this research was to foster indigenous Mexican crafts, it is important to analyze the means by which I intended to do so. The following research questions aim to inform the effectiveness of fostering the practice of traditional crafts throughout the project's realization:

- What would be the effects of indigenous Mexicans participating in the global fashion marketplace?

- Which are the best practices or strategies that would foster collaboration with indigenous Mexican craftspeople in an ethical and respectful way? 


\section{Researcher's Background}

I hold an Honours Bachelor of Textile Design degree (2002) from Universidad Iberoamericana, in Mexico City. During this program I had the opportunity to work with an indigenous Mexican community in Puebla ${ }^{1}$ where I learned about the difficulties this community experiences. Moreover, I have always been interested in the cultural differences existing in Mexico. Martinez-Echazabal (1998) explains that mestizaje is "the process of interracial and/or intercultural mixing" (p. 21). Vasconcelos argues that this process started in Latin America with the Spanish colonization and thus two racial and cultural groups continue to live concurrently (as cited in Alonso, 2004, p. 464). The first group is the indigenous Mexicans, and the second one is the result of mestizaje between Spaniards and indigenous Mexicans.

My grandfathers were Spanish and Japanese and both of my grandmothers were indigenous Mexican descendants. I was born and raised in Mexico City, thus I belong to the second group. Even though my physical characteristics are not exactly Mexican, the Mexican culture is implicit in my way of being. Berger (2015) discusses the advantages and disadvantages of the researcher's position — either as an insider or stranger. In my case I believe I am both: an insider and a stranger. While my physical appearance could be a barrier between me and indigenous Mexican artisans, I have lived seeing them and interacting with them all the time: in the streets, markets, near my home and school. Therefore, I have some knowledge about their lives, which allows me to know how to approach them or how to talk to them; I am not a complete stranger. However, I am not part of their community; I am not one of them. I am aware of our similarities and our differences and I accept them and respect them. Having a combined researcher position as an insider and stranger simultaneously was as challenging as it was beneficial, and I aimed to leverage both situations.

\footnotetext{
${ }^{1}$ Puebla is a Mexican state located in the central part of Mexico.
} 


\section{Theoretical Framework}

Moxley (2013) posits that through social work, art-making supports communities trying to survive oppression and in turn strengthens their cultural identity. Therefore, social practice was used as the overall theoretical framework to empower indigenous Mexican communities through fostering their crafts. According to Reisch and Jani (2012), social practice "strives to promote social change, empowerment and human liberation by integrating data-driven research and analysis" (p. 1133) through the lens of social justice. Such a framework will point out strategies to help Mexican indigenous communities improve their well-being and strengthen their cultural identity.

My research proposes fashion design as the means by which indigenous Mexican craftspeople will increase their confidence and consequently empower themselves. Furthermore, Navarro (2014) hybridized social practice and fashion as a way to "encourage dialogue on influencing change at a societal level" (p. 454) in a theoretical model he called "Social Practice Fashion" (p. 454). Therefore, these two theoretical approaches (social practice and social practice fashion) provide a unified framework to analyze and evaluate my data. I anticipate that fostering textile crafts traditions as part of the fashion design practice will increase selfconfidence among participating Mexican indigenous craftspeople, who will be the ultimate beneficiaries of my project's social practice objectives.

\section{Literature Review}

There is a short story that captures the key ideas of my research project: Bruno Traven's (1960) tale "Canastitas en Serie" from his book Canasta de Cuentos Mexicanos. Wood (2000) analyzes different versions of Traven's story. "Canastitas en Serie" is a tale that implicitly shows the way indigenous Mexican artisans think and work. This tale touches important aspects 
concerning my research and guided me toward the potential outcomes I wanted to achieve. I will briefly summarize the version of this tale as discussed by Wood (2000). Afterwards, I will explain the selected topics explored through the study's literature review and their connection with the tale.

\section{Canastitas en Serie (Series of Little Baskets)}

The story is about an old indigenous Mexican man who created multicoloured baskets out of palm leaves. One day, while he was selling the baskets in the market, an American man wanted to buy one of them. The price of each basket was 2,500 Mexican pesos (approximately US\$0.82 at that time), regardless of how plain or elaborated in design. The American was amazed by the baskets' beauty and inexpensiveness, therefore he wanted to buy more of them to resell back in United States. He asked the indigenous artisan how much it would cost to buy all of the baskets and if he could get a discount for buying them in bulk. The artisan answered that

the price remained the same. No matter how much the American man bargained, he could not get a lower price. In a desperation, the American asked if he could get a lower price by buying a thousand baskets, to which the artisan responded "the price for 1,000 baskets is $4,000,000$ [Mexican] pesos" (Wood, 2000, p. 188), which brought the price of each basket at 4,000 Mexican. The American could not believe this, so the artisan explained:

Each of these baskets I make with my own two hands, all of the designs and colors are my own, and a piece of my heart goes into each and every one of these little baskets. Sir, one thousand baskets would drain my heart. ... I would be left with no heart to weave my baskets and that is why 1,000 baskets cost so dear. (Wood, 2000, p. 188)

This tale expresses the connection between the indigenous Mexican artisan and his work, which is unique and authentic. It also brings to the forefront the contrast between mass 
production and small quantity production of meaningful items. The time invested in the production of a single basket multiplied by a thousand also illustrates topics of ethical labour and fair trade. Based on this tale, it becomes evident that in order to preserve the artisan's cultural legacy, empowerment can be of a great value. Hence, the themes reviewed include: cultural empowerment, legacy and cultural appropriation, design, crafts and storytelling, ethical labour and fair trade, and environmental awareness and slow fashion.

\section{Cultural Empowerment}

Foley (1997) suggests that empowerment is used in different contexts before defining it as the phenomenon occurring when "Individuals take over their own destinies, creating alternative movements and forms of development" (p. 2). Moreover, Foley argues that those individuals have to be oppressed by a dominant culture. Foley also establishes different ways to achieve empowerment and divides them as follows: democratic, economic, political, environmental and cultural (1997, pp. 21-23). Cultural empowerment concerns the reinforcement of cultural values. Therefore, for my research goal I sought to empower indigenous Mexican craftspeople through cultural as well as economic means as suggested by Foley. During the literature review, I found it interesting how Stephens and Tiwari (2015) empower marginalized groups by recovering their heritage, and Maguirre, Ruelas, and Torre (2016) are concerned with indigenous women's empowerment.

"Social enterprise" is a term I found to be relevant to my research as well. Levander (2010) describes it as "a complex set of discourses within an institutionally constructed narrative designed to build identity and gain legitimacy" (p. 213). The author offers an implementation analysis of the social enterprise model. Levander also explains social enterprise as "business with the aim to integrate people in society and in the labor market" (2010, p. 214), while reinforcing 
identity and legitimacy amongst marginalized groups. Within my MRP, I consider the idea of social enterprise as a complementary tool for supporting empowerment of Mexican groups. Moreover, such empowerment resulting from fostering indigenous Mexican traditional crafts through the creation of a swimwear line has not been examined previously.

\section{Legacy and Cultural Appropriation}

There is great amount of scholarly literature about preserving cultural legacies. I was pleased to see that research about Mexican arts and crafts is considerable. However, most scholars have focused mainly on Oaxacan indigenous groups while craft traditions from other areas of Mexico have not been studied as much.

Garcia and Vinebaum (2016) provide valuable insights on culture legacy in their article based on an interview with Ana Paula Fuentes, the Director of the Oaxaca Textile Museum. The museum's main objective is to support local craft traditions and textile artisans. In the interview, Fuentes states "So much of what used to be produced by hand is done now industrially using machines ... as a result, gradually many of the crafts have been lost and with them part of the traditions of our culture as Mexicans" (Garcia \& Vinebaum, 2016, p. 125)— that is to say, globalization and technology not only are putting textile traditions at risk but the low value attributed to textiles also has negatively contributed to the industry as well. Fuentes also highlights foreigners commissioning artisans to do other kinds of designs. As a consequence, the artisans aren't using their own motifs, "resulting in a total loss of the designs and by extension a loss of identity" (Garcia \& Vinebaum, 2016, p. 126). These authors provide important information regarding the influence that Western society and globalization have in preserving indigenous arts and crafts. Moreover, they suggest strategies to successfully help these artisans' communities to preserve their cultural heritage. 
Lynn Stephen (1987) also examines the preservation of cultural heritage and how helping indigenous communities may strengthen their cultural identity and traditions. Stephen analyzes the indigenous Zapotec community of Teotitlan Mexico, and her findings include examples of how capitalism may be used to support cultural identity. The commercialization of their crafts has helped this community of traditional Zapotec weavers economically while their cultural identity has been reinforced (Stephen, 1987). Stephen also demonstrates how the economic growth of the community of indigenous weavers goes hand in hand with an increase of ritual and ceremonial gatherings. Indeed, she points out that these rituals not only increased in number but also shifted in character; before, the rituals were focused on venerating Catholic saints but more recently they consist of family-related ceremonies such as baptisms and weddings (Stephen, 1987, para. 7). Even though there is information and research about how to preserve cultural legacies among indigenous communities, no studies outline strategies to foster traditional crafts practices without being detrimental to indigenous identity and legacy.

While conducting a preliminary literature review for the present study, it became evident that cultural appropriation is a very relevant topic for my research. I decided to widen my knowledge about that topic in order to accomplish my creative research objectives in a socially responsible yet culturally respectful way. In its usage, cultural appropriation involves a wide range of meanings. For example, Huck (2012) defines cultural appropriation as "to make a thing one's own.... Cultural appropriation thus, deals with objects that are first perceived as being strange, foreign or simply new and then gradually become more familiar" (p. 77). This same perspective is shared by Marks (2015) as well as by Ibarra and Strawn (2015), who discuss appropriation as creating something new while adding different values and meanings to those new items. Huck (2012) also argues that appropriation is not "a unidirectional activity" (p. 78). This is consistent with how Stephen (1987) places the indigenous community as the ones 
appropriating: "the history of development in the community provides useful insights for how indigenous communities can appropriate economic development for their own use" (para. 3). However, the types of cultural appropriation discussed by Stephen and by Huck do not represent a threat to indigenous groups.

For the purpose of this research, these types of cultural appropriation are not seen as unethical. What I consider detrimental is when cultural appropriation "includes also those acts where individuals, companies, or institutions fashion objects in order to 'sell' them, either within their own or to another culture" (Huck, 2012, p. 78). Pham (2016) has conducted several studies about this type of cultural appropriation, arguing that "acts of appropriation are rooted in and reproduce a relationship of unequal status and power" (p. 51). Therefore, it is the marginalized groups who are being affected. These analyses benefit my research in helping to establish the boundaries as to how appropriate indigenous designs can be incorporated in way that is not exploitative or detrimental to the cultural legacies and identities - for example, by giving recognition (monetary and authorship) versus advantageously appropriating their designs with unfair or no remuneration or recognition.

Finally, some research has focused on cultural appropriation of Aboriginal New Zealand motifs used in contemporary swimwear. According to Shand (2002), an agreement was made between the Aboriginal group and the swimwear manufacturer and recognition (monetary and authorship) was given to the Aboriginal New Zealander groups. Even though there are cases of Mexican art being culturally appropriated, there is little research that documents this.

\section{Design, Crafts, and Storytelling}

The garment designs for my proposed swimwear line will be unique and authentic because indigenous Mexican craftspeople will embroider them. Some researchers have examined the aesthetic impact that handmade articles have on consumers. For example, Luckman (2013) 
suggests that handmade items give the consumer a feeling of uniqueness that stands out in an “inauthentic world" (p. 254). Moore and Prain (2009) and Waterhouse and Levine (2010) discuss about knitting/crocheting/DIY as a way that "craftivism" stands against the values of corporate consumerism and mass-produced goods. Moore and Prain (2009) even consider crafts to be a “political statement” (p. 22). Therefore, wearing pieces from the study's swimwear collection created through this research may represent a statement against mass-produced goods and thus support Mexican indigenous craft traditions.

As mentioned before, each piece of the swimwear collection will have a story to tell that will connect it back to the wearer. Gauntlett (2011) states that "creativity usually involves at some point, a social dimension and connects us with other people" (p. 10). Gauntlett's book is helpful for my research because it provides insights into how social connection is established through the process of design. As Gauntlett notes, "making things and sharing them in the world, we increase our engagement and connection with our social and physical environments" (p. 10). Therefore, through their traditional craft making, the indigenous Mexican people can be connected with people around the world.

Mexican indigenous groups imbue their designs with stories, feelings, and traditions. In order to transmit this to the wearer, it is essential to document all those meanings and the feelings of the artisans while they work. The magazine Artes de México's article titled “Textiles de Oaxaca" (Artes de Mexico, 1996) contains valuable information about the meaning of Oaxacan huipiles $^{2}$ and the traditional motifs used. Furthermore, in the editorial the latter volume, the author De Orellana (1996) describes how the hands of Oaxaca weavers are like voices that imbue their crafts with their culture, myths and daily life (p. 7). Hence, the Artes de México volumes

\footnotetext{
${ }^{2}$ Huipil is an embroidered sleeveless blouse or tunic made by Mexican or Guatemalan indigenous women. The technique used to fabricate huipiles is Backstrap loom which dates from pre-Columbian times and it is passed down for generations (Lechuga, 1996).
} 
titled "Textiles de Oaxaca," "La Tehuana," and "Textiles Mazahuas" (Artes de México, 1996, 2000, 2011, respectively) are important publications that provide knowledge about the significance of textiles transmitted by other indigenous groups from Mexico.

\section{Ethical Labour and Fair Trade}

Historically, ethical labour and fair trade are problematic issues in the fashion industry. The manufacturing of fashion products has been linked to exploitation and gender discrimination (Wilson, 2003) - from the hatters endangered by the mercury used to felt hats back in the 17th century, to the 21 st century factories in developing countries where workers are exploited and discriminated. The research undertaken on these subjects is of a great value to my own research. An understanding of ethical labour and fair trade is needed in order be contribute to the process of empowering indigenous communities and guarantee fair working conditions.

According to Dissanayake, Perera, and Wanniarachchi (2017), "Fair trade aims to support farmers and craftsmen who are socially and economically marginalized" (p. 2) and also increases the "trust-worthiness" (p. 2) of the community. However, not everyone agrees on the benefits of this system, and the concepts surrounding fair trade are controversial among scholars. For example, Dragusanu, Giovannucci, and Nunn (2014) discuss the position of some scholars who think that fair trade promotes poverty instead of reducing it. They criticize this system as being inadequate to help workers economically and suggest that transferring funds directly to workers communities is a better approach than fair trade (p. 234). However, this may give rise to other types of social conflict. I find all of the points touched on by Dragusanu et al. very helpful for my research because they enumerate all the requirements for participation in the fair trade system, such as certifications. But more importantly, Dragusanu et al. objectively point out the pros and cons of fair trade practices. 
Powel and Zwolinski (2012) show another perspective of the fair trade argument and discuss the advantages and disadvantages of the sweatshop model; what is interesting in their article is that they point out that unfortunately "sweatshop labor often represents the best option available for desperately poor workers to improve their lives ... [and] any attempt to reform sweatshops must proceed with caution, lest the incentives that produce this benefit be destroyed" (p. 449). Powell and Zwolinski have a very particular perspective regarding fair trade, implying that even though the work conditions in sweatshops are not the best, sometimes they are the only options that some communities have. As such, my MRP research considers the present working conditions in the participating communities, instead of changing or recreating them completely. As I mentioned earlier, ethical labour and fair trade are topics extensively researched, however I did not find anything regarding fair trade in the swimwear industry.

\section{Environmental Awareness and Slow Fashion}

In order to make indigenous traditional crafts fully valued, it is important to research the impact of environmental awareness in the global marketplace and the social importance of the slow fashion movement. Fletcher (2010) argues that the term "slow fashion" has been interpreted as the opposite of fast fashion: slow and fast fashion "are different worldviews, with different economic, logic, and business models, values and processes" (p. 262). The slow-fashion movement and environmental awareness are subjects widely explored in existing scholarship. For example, according to Fletcher (2007), Jung and Jin (2016a, 2016b), Ozdamar Ertekin and Atik (2015), Pookulangara and Shephard (2013), and Dissanayake et al. (2017), there is a growing interest in environmental health awareness and on consuming quality products. Ham, Mrcela, and Horvat (2016) define environmental awareness as "the attitude regarding environmental consequences of human behaviour" (p. 160). Concerning the fashion industry, this awareness translates into the slow fashion movement. 
Fletcher (2010) and Jung and Jin (2016) note that slow fashion followed the slow food movement created by Carlo Petrini. Similarly to slow fashion, the slow food movement stands against "the proliferation of corporate-centered dynamics such as fast food restaurants" (Jung \& Jin, 2016, p. 2). Therefore, if we follow this dynamic, we are directing ourselves towards building a sustainable fashion industry. Fletcher (2007) maintains that "Slow fashion is about designing, producing, consuming, and living better. . . . It is not time-based but quality-based" (p. 61). This new economic environment or way of life proposed by slow fashion could easily integrate indigenous Mexican arts and crafts practices. Moreover, it also supports consumer values about fashion given the work involved in producing items that integrate indigenous crafts. In sum, even though there is research about consumers interested in slow fashion practices, there is no information about slow fashion as it applies to swimwear or the environmental concerns related to the swimwear business.

\section{Methodology}

This study's objectives were to identify the impact of commercializing traditional Mexican crafts in a respectful way and to unravel some guidelines to work with indigenous Mexican groups to foster and preserve their traditions. Therefore, I utilized multiple methods based on advocacy/participatory research. Creswell (2003) states that marginalized groups can be helped through advocacy, and that this method is about bringing change to improve research participants' lives.

Given the fact that my research is related to indigenous Mexican communities, Smith's (2012) research on indigenous methodologies was very useful. Smith merged 25 indigenous projects with methodologies to improve and facilitate indigenous research, which includes storytelling. As Smith points out,

new stories contribute to a collective story in which every indigenous person has a place. 
$\ldots$ The story and the story teller both serve to connect the past with the future, one generation with the other, the land with the people and the people with the story. (p. 145)

The objective of my research was to learn about the life of Mexican artisans and how their own story has contributed to the present situation of Mexican indigenous crafts. Therefore, I designed interview protocols for this study in consultation with Ryerson University' Research Ethics Board (REB), which reviewed and approved my research methods. The aim of these interviews was to learn more about the histories behind the creative processes of indigenous Mexican craftspeople, including how they have changed over the years. The connection between indigenous Mexican artisans and their work and their feelings about being valued and fairly remunerated were analyzed through the interviews as well. During the interviews, I also asked about the experiences of indigenous Mexicans while selling their work and the problems associated with commercializing their wares. The outcomes of agreements between designers and indigenous artisans were another aspect also touched upon during the interviews.

I divided the methods into four phases. During phase 1, I observed the kind of crafts sold in Mexican markets to identify the possible crafts that would be suitable for the swimwear collection. Phases 2 and 3 involved conducting interviews with: (a) designers who collaborate with Mexican artisans; (b) organizations that provide support to Mexican communities to improve their quality of life; and (c) Mexican artisans. Phase 4 was about the swimwear creation process. Figure 1 and Table 1 outline all of the methods employed in this research project. 


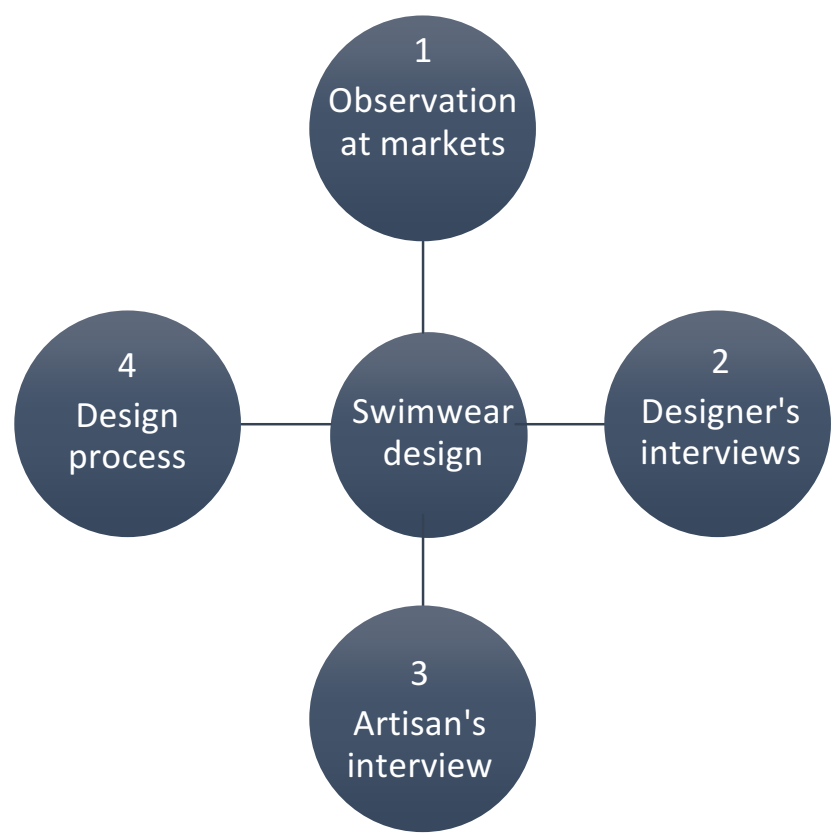

Figure 1. Methods utilized, divided into four different phases.

Table 1

Summary of Methods and Guiding Questions

\begin{tabular}{|c|c|c|c|}
\hline Phase & Method & Detail & Guiding questions \\
\hline 1 & $\begin{array}{l}\text { Observation and } \\
\text { market visual } \\
\text { content analysis }\end{array}$ & $\begin{array}{l}\text { - Walk through the } \\
\text { markets to see what kind } \\
\text { of crafts are being sold. } \\
\text { - Analyze the different } \\
\text { types of craft and classify } \\
\text { them by type and region. } \\
\text { - Determine the type of } \\
\text { crafts that can be used in } \\
\text { the swimwear line. }\end{array}$ & $\begin{array}{l}\text { - How are the crafts being exhibited? } \\
\text { - Where are the crafts from? } \\
\text { - What type of crafts are there? } \\
\text { - How are the crafts organized throughout the } \\
\text { market? } \\
\text { - Are the crafts in the market produced by the } \\
\text { artisans that are selling them? } \\
\text { - Which kind of crafts may potentially be used in } \\
\text { swimwear garments? }\end{array}$ \\
\hline 2 & $\begin{array}{l}\text { Designer's } \\
\text { interviews } \\
\text { (Group } 1 \text { and 2) }\end{array}$ & $\begin{array}{l}\text { - Understand the way the } \\
\text { designers work or } \\
\text { collaborate with Mexican } \\
\text { indigenous. } \\
\text { - Identify the advantages } \\
\text { and disadvantages of the } \\
\text { partnership between the } \\
\text { designers and Mexican } \\
\text { indigenous. }\end{array}$ & $\begin{array}{l}\text { - Are the designers working with the same } \\
\text { indigenous group all the time? Do they change } \\
\text { groups depending on their collections themes? } \\
\text { - Which parts of the garments are being produced } \\
\text { by the indigenous Mexican craftpeople? } \\
\text { - Are the Mexican indigenous motifs used } \\
\text { exactly as they are or the designers modify } \\
\text { them to be more appealing to their clients? } \\
\text { - Are the artisans provided with a place to work } \\
\text { by the designers? }\end{array}$ \\
\hline
\end{tabular}




\section{Table 1}

Summary of Methods and Guiding Questions (Cont'd)

\begin{tabular}{|c|c|c|c|}
\hline Phase & Method & Detail & Guiding questions \\
\hline 2 & & & $\begin{array}{l}\text { - Are the garments produced with the artisan's } \\
\text { materials or the designers provide them with } \\
\text { different ones? } \\
\text { - What kind of benefits this way of work brings } \\
\text { to the indigenous Mexican artisans? }\end{array}$ \\
\hline 3 & $\begin{array}{l}\text { Artisan's } \\
\text { interviews } \\
\text { (Group 3) }\end{array}$ & $\begin{array}{l}\text { Understand the artisan's } \\
\text { creation process and its } \\
\text { evolution. }\end{array}$ & $\begin{array}{l}\text { - How the indigenous artisan learned the craft? } \\
\text { - Are the techniques and materials used to } \\
\text { elaborate the crafts still the same? How have } \\
\text { they changed? } \\
\text { - Are motifs and colors the same? How they have } \\
\text { changed? } \\
\text { - Do the artisans enjoy craft making? } \\
\text { - Do the artisans like to sell their crafts? } \\
\text { - Which are the problems the indigenous } \\
\text { craftspeople are confronted while selling their } \\
\text { wares? } \\
\text { - Is there special connection between the } \\
\text { indigenous traditions and their crafted work? } \\
\text { - Are there special reasons to use certain motifs? }\end{array}$ \\
\hline 4 & $\begin{array}{l}\text { Creation of the } \\
\text { swimwear line }\end{array}$ & $\begin{array}{l}\text { Analyze the findings to } \\
\text { establish respectful } \\
\text { strategies to foster craft } \\
\text { traditions among Mexican } \\
\text { indigenous. }\end{array}$ & $\begin{array}{l}\text { - Which are the best practices to help indigenous } \\
\text { Mexican craftspeople? } \\
\text { - Which strategies foster indigenous Mexican } \\
\text { craftspeople to continue producing in their } \\
\text { traditional way. } \\
\text { - From a designer perspective, which are the best } \\
\text { ways to merge craft traditions into the fashion } \\
\text { marketplace without detriment of indigenous } \\
\text { traditions? }\end{array}$ \\
\hline
\end{tabular}




\section{Observation}

Phase 1. To accomplish the first phase of the research, I decided to focus on the market La Ciudadela (The Citadel) located beside the Mexican Historic Centre in Mexico City. One of the reasons why I chose to concentrate on this specific market it is because La Ciudadela gathers Mexican crafts from all over the country, making it easy for tourists or anyone else to find PanMexican crafts in one place. The market is organized by aisles surrounding a central open terrace where art expositions, traditional music shows, or dances are held. There are well-structured stores as well as stalls. The well-structured or bigger stores are predominantly managed by retailers who sell different crafts from different parts of the country. Meanwhile, the small stalls belong to independent crafts producers, who often times are there working on their crafts on-site. It is very easy to identify the retailers from the producers. There are all kinds of crafts on display such as textiles, ceramics, jewelry, and musical instruments.

\section{Interviews}

Phase 2. The objective of this phase was to interview designers (group 1) whose work is inspired or designed in collaboration with Mexican indigenous groups and people working for associations, institutions, or museums (group 2) in charge of improving the quality of life of indigenous Mexican groups.

Participants in group 1 were recruited by phone from information that is publicly available through their websites and/or social media. Two designers were recruited but only one consented to participate. The participants of group 2 were also recruited by phone from information that is publicly available through their websites and/or social media. The objective was to interview two or three participants from different institutions or museums. Regretfully, due to the formalities of the REB protocol I was unable to obtain participation consent. The 
participants I recruited were willing to be interviewed, however they did not want to sign the consent form or be audio recorded. There has been a great amount of negligence and corruptionrelated problems in Mexico, and these issues have been publicly exposed in social media through video or audio recorders. There is much fear about any kind of exposure, therefore the participants refused to sign any paper or be audio recorded.

Phase 3. The aim of this phase was to interview members of different indigenous Mexican communities (group 3) who practice their craft traditions as a way to provide themselves and their families with economic support. They were recruited in two different ways: the first way was to approach them directly while they sold their crafts in the markets. When I went to La Ciudadela to complete my observation as intended in phase 1, the plan was to identify possible candidates to interview as well. As I first approached the artisans to introduce myself and explain my research purpose in order to see if they were interested in participating, I noticed they were intimidated by the formalities of the REB approval interview protocol, and they refused to participate immediately; therefore, I changed my strategy. Instead, I started asking them about their products first and then about their craft origins; at this point they were very participative and answered any kind of question, showing me details of their work. Thus, once I had established a rapport with them, I introduced myself and explained my research to further ask if they would like to participate. Nevertheless, as soon as I started to explain my research they would turn away and say no thank you, without even letting me finish the explanation.

It was a very frustrating experience, and I finished the day with zero candidates to interview. However, that day I was able to talk with seven artisans (off the record). After this experience, a friend of a friend took me to a smaller market where she knew an artisan who accepted to participate because she trusted my friend and therefore she trusted me. 
The second method of recruitment was through institutions, museums, or designers collaborating with such communities. I approached Mexican artisans working in collaboration with the designer I interviewed and I recruited another participant. Similarly, this second participant agreed to be part of my research because she trusted the designer for whom she works, and therefore she trusted me. The consent process for the artisans was an explicit verbal consent because of language and illiteracy issues ${ }^{3}$. I conducted in-person interviews with the three participants, which were audio recorded. A descriptive analysis of the data set was completed and is located in the Discussion section of this paper. All the information obtained from the interviews is confidential and there aren't any identifying elements such as names on the interview transcripts. The names are coded and the key to the code is kept locked in a secure location.

The effectiveness of the empowerment through fostering traditional crafts practice was explored in the literature review as well as by questions included in the interview with the designer, whose work was based on Mexican traditional crafts and/or collaboration with indigenous groups. In an attempt to measure the benefits of this collaborative agreement between the designer and indigenous groups, I asked questions about the outcomes and the changes in the indigenous groups well-being. I explored the terms of these collaborations to determine which approaches or strategies support empowerment among indigenous communities.

\section{Design Process}

Phase 4 comprised a creative component with the objective of creating meaningful pieces while integrating indigenous Mexican textile crafts. Furthermore, capturing how Mexican

\footnotetext{
${ }^{3}$ The official Mexican language is Spanish, however there exists a great number of dialects practised by different indigenous communities within Mexico. Even though such indigenous communities may speak Spanish too, it is very unlikely they will know how to read it because of the lack of education services in the country.
} 
artisans think and feel about their work was very important for my research. After all, those feelings were imbued within the swimsuits. The motifs used and the type of embroidery depended on the artisan's creative interests and his/her cultural identity.

The artisans' respective culture, beliefs, and personality are captured in the pieces created by them. Benjamin (1936/2005) said that authenticity is directly related to the originality of an object and how and when it was created; he stated that "The uniqueness of a work of art is inseparable from its being embedded in the fabric of tradition" (p. 6). He calls this phenomenon "aura" and thus the textile crafts created by indigenous Mexican artisans have an aura because they are authentic and imbued with culture and traditions. Furthermore, in order to represent the "inauthentic" (Luckman, 2013, p. 254) mass-produced item in contrast to the authentic ethically responsible fashion product, I aimed to give "aura" to a mass-produced garment.

Therefore, I bought mass-produced swimsuits in one of the biggest worldwide fashion chain stores (see Appendix A for swimsuits photos). The pieces were inexpensive, with the price each garment price varying from about $\$ 7$ to $\$ 20$ Canadian dollars. I then took the garments to Mexico, and I recruited several indigenous artisans to embroider the swimsuits however they saw fit. After conducting interviews with two Mexican artisans, they showed me their work and the kind of craft they normally do. I realized their work was very skilled and beautiful. Therefore, I asked them if they wanted to work with me to embellish some garments, to which they both agreed. Thus I gave them the swimsuits and asked them to embroider the garments with whatever motifs or techniques they felt like.

As mentioned earlier, the purpose of this project was to create unique swimwear garments with a story embedded in them. Moreover, I wanted the indigenous Mexican artisans to create their part completely by themselves. At this point I did not consider the final aesthetic of 
the swimsuits or functionality to be important. I wanted to focus on the process of making and on the artisan's own personal creative actions. I anticipated the challenges that might arise: first, the biggest problem was the kind of fabric; swimsuits are normally made of a polyester/nylon and spandex blend. This makes the fabric elastic and also difficult to embroider. One of the artisans had never worked with elastic fabrics before, but the other one had. Thus, it was very interesting to see how they both dealt with this technical challenge.

The second issue was that they both were assigned a bikini top with pre-formed breast cups, which further complicated the embroidery process. Another issue I did not expect was that they both felt very uncomfortable with the project because they were given complete liberty to decide what to embroider on the garments. This surprised me, especially because they both are excellent embroiderers and have been doing this all of their lives.

\section{Artisan \#1}

Unfortunately, I met with Artisan \#1 only two times, which forced her to accomplish the embroidery completely on her own. As noted above, and given the fact that I asked her to embroider the swimsuits any way she wanted, I noticed a lack of self-confidence. Therefore, the fact that I could not establish contact with her during the embroidering process forced her to trust her own creative instincts and skills. During our first meeting I interviewed her and she explained to me the way she learned to embroider and her ways of selling her products. She comes from San Pablito (see Figure 2), a little town in the state of Puebla and she is part of the Otomí $^{4}$ community.

\footnotetext{
${ }^{4}$ The Otomí community is an indigenous group that live dispersed in the central part of Mexico. The production of amate paper and handicrafts such as bead jewelry and embroidered blouses are part of the economic activity of the Otomí group (D’Aubeterre Buznego \& Rivermar Pérez, 2014).
} 


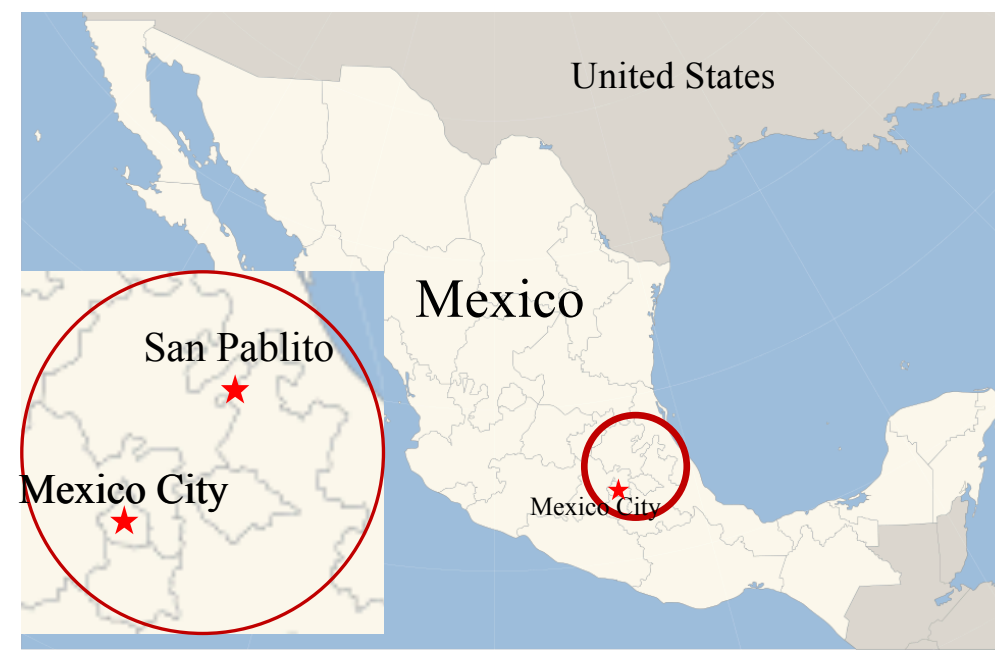

Figure 2. Map of Mexico-San Pablito. Artisan \#1 comes from San Pablito, which is located North East of Mexico City. Source: Keepscases - Own work, CC BY-SA 3.0. Retrieved from https://commons.wikimedia.org/w/index.php?curid $=9084900$

Artisan \#1 has always supported herself and her family by selling her work in different ways. Presently she works for a designer who produces fashion in collaboration with several Mexican artisan communities. Working with this designer, she has learned to manipulate different kinds of fabrics other than the traditional textiles. She also gained experience and self-confidence when commercializing her crafts, including determining a fair price for her efforts and skills.

Afterwards, I gave her two bikinis to embroider and we agreed to keep in touch to follow her progress. Due to different circumstances I lost contact with her, and only on my last try to reach her could I set an appointment to see her progress. During this meeting I was very happy to see that she had finished both bikinis and the result was amazing. I was extremely pleased to see how beautiful the embroideries were. She applied her heritage to these mass-produced modern pieces in a very smart way.

Swimsuit \#1: Beaded bikini. The first bikini she showed me was beaded (Figure 3). She explained that she chose different colours because she likes colourful things and she wanted the motifs to be joyful and cheerful. She outlined the shapes of the bra and bottoms of the bikini with 
little beaded flowers and placed a little beaded bird in the middle of each bra cup and in the face of the bikini bottom (Figure 4).

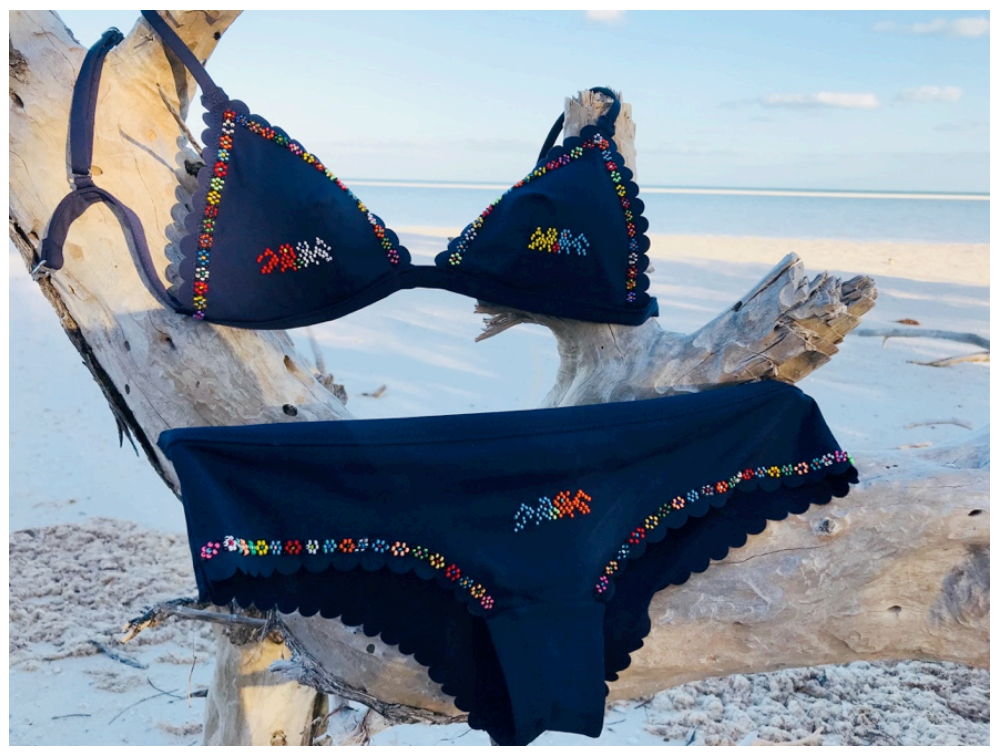

Figure 3. Bikini beaded by Artisan \#1 with a beaded bird motif. Photo by Hoshiakari Endo Portillo.

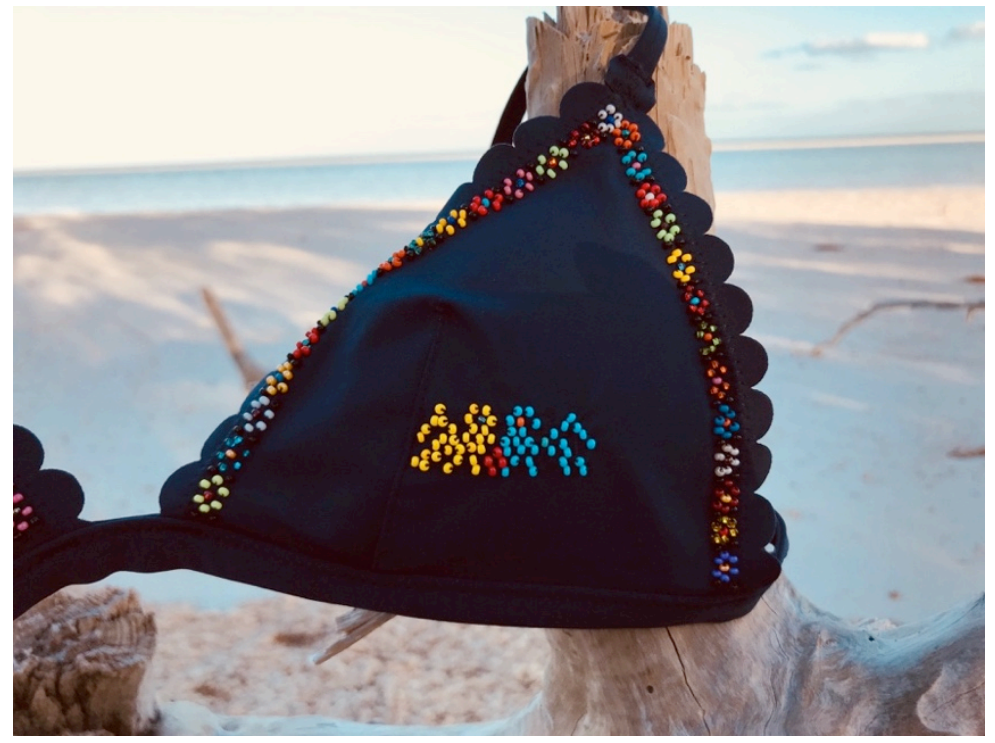

Figure 4. Beaded bikini detail. The motif in the centre is a beaded bird. Photo by Hoshiakari Endo Portillo. 
Swimsuit \#2: Bikini embroidered Tenango style. The principal criteria I used to choose the mass-produced swimsuits I purchased was that the garments were plain, textureless, monochromatic, and inexpensive (see Appendix A for swimsuit photos). However, it was not the case with this bikini, which had white and navy stripes. I had noticed that last summer, the fashion retail landscape was permeated by stripes and embroidered garments. Moreover, swimwear trends follow fashion trends 1 year behind. Therefore, when I saw the striped bikini, I decided to include it in the project.

This bikini (Figure 5) was embroidered by the artisan in a traditional style known as Tenango ${ }^{5}$. The motif embroidered was a hummingbird with a flower (Figure 6). The colours she chose for this embroidery are softer hues than the ones used on the beaded bikini. Her objective this time was to express peace and love.

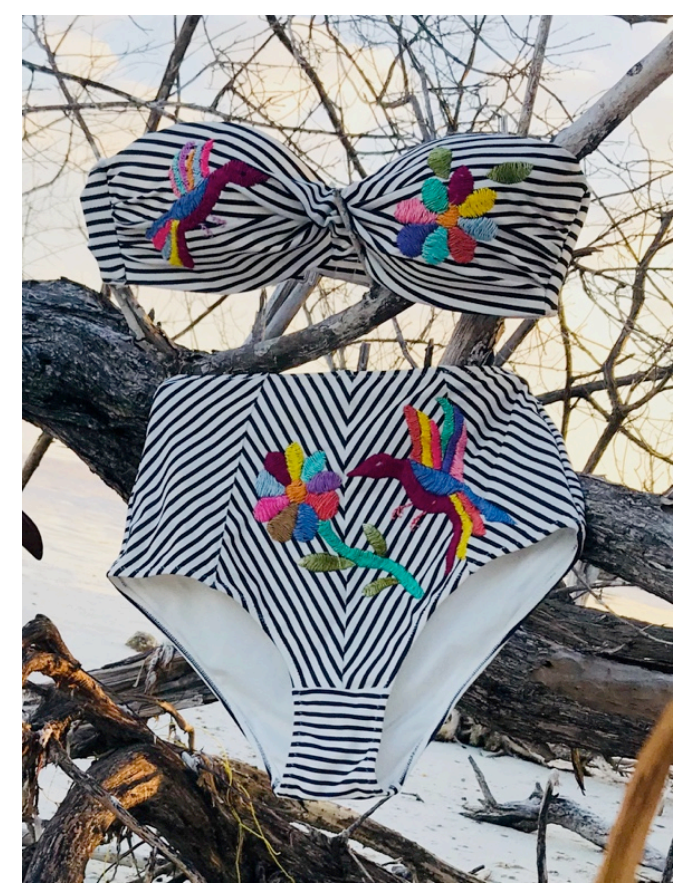

Figure 5. Bikini embroidered by Artisan \#1 like a Tenango. Photo by Hoshiakari Endo Portillo.

\footnotetext{
${ }^{5}$ Tenangos are colorful embroideries made by Otomi communities from Tenango de Doria in the state of Hidalgo. They are embroidered mainly over cotton muslin. Tenangos are inspired by local flora and fauna and they depict the way of life of the creators (Cardenas, 2016)
} 


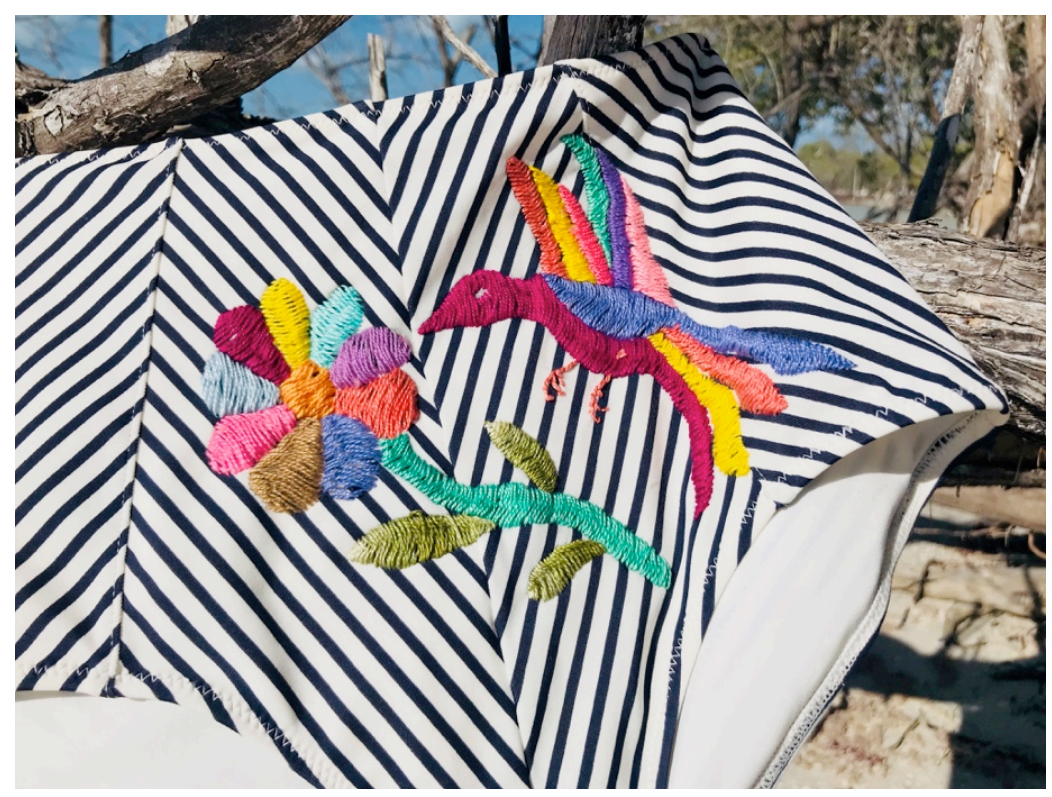

Figure 6. Embroidered bikini detail. Hummingbird with a flower. Photo by Hoshiakari Endo Portillo.

In the article "Of Birds and Insects: The Hummingbird Myth in Ancient Mesoamerica," Mazariegos (2010) examines all the different versions of the hummingbird myth in Ancient Mesoamerican cultures. It is very interesting to point out how birds in general and hummingbirds in particular have been an important symbol in ancient Mexican culture. Even though it is very common to find all kinds of birds embroidered on the Tenangos, and given the importance of the bird significance in Otomi heritage, I was curious to know why she decided to depict birds in both swimsuits. When I asked, she answered "women have more dreams than men do; women have wings."

Regarding the technical skills used to embellish the bikinis, I found they were excellent. As I mentioned earlier, two of the biggest issues were to be able to embroider elastic fabrics and a pre-formed breast cup. Artisan \#1 was able to perfectly embroider the elastic fabric without wrinkling the fabric, with even letting space for the fabric to stretch without tension. Moreover, she left no trace of the embroidery in the inside of the swimsuit. The second challenge was very well managed also; she was able to embroider over the pre-formed breast cup without deforming it. The fact that she had worked with a designer who taught her how much to fairly charge for her 
work was important as well. She knew exactly the time she invested in the embroideries and consequently priced her work correctly.

\section{Artisan \#2}

The process with Artisan \#2 developed differently than with Artisan \#1 because we had the opportunity to meet four times. During the interview conducted in our first meeting, she explained that although her passion is to embroider, she has to have another source of employment to be able to support her extended family economically. She actively embroiders; she is always trying to find a moment to do it, either in between shifts, during short breaks at work, or at night. She mainly embroiders cloth napkins with different motifs and in different sizes and shapes. Moreover, she is able to sell those napkins or donate them to be used during festivities in her community. She comes from Atlacomulco, Estado de México (Figure 7) and belongs to the Nahua ${ }^{6}$ community, but presently resides with her husband in another town of Estado de México.

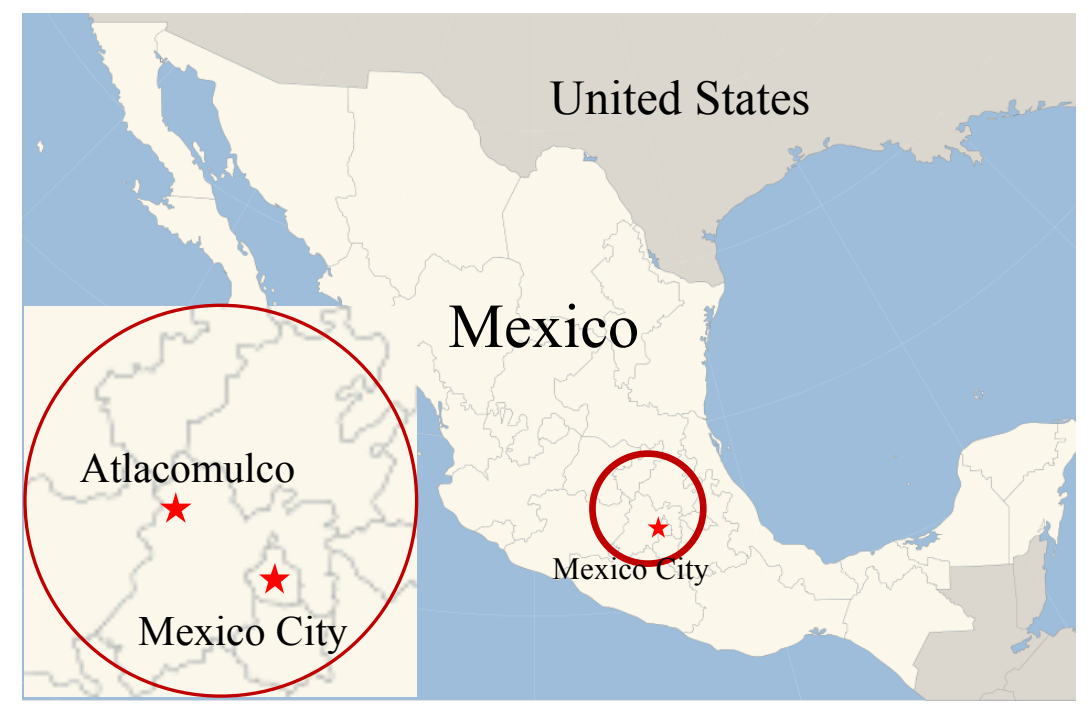

Figure 7. Map of Mexico- Atlacomulco. Artisan \#2 comes from Atlacomulco, which is located North West of Mexico City. Source: Keepscases - Own work, CC BY-SA 3.0. Retrieved from https://commons.wikimedia.org/w/index.php?curid=9084900

\footnotetext{
${ }^{6}$ Nahua is an indigenous group stablished in the central part of México and they are a direct descendant of the Aztecs (Gobierno del Estado de México, 2018).
} 
Artisan \#2 mentioned that her sons and daughter learned how to embroider and that they all enjoy doing it. I found it very interesting how much she relies on her children to help her develop some embroideries, and her children, in turn, rely on technology to help her. For example, she explained that if she wants to embroider a flower, she asks her son and he prints for her a flower drawing from the Internet. Once the interview concluded, and after showing me the kind of embroidery she does, I proceeded to show her two of the swimsuits and the cover-up I assigned to her. Similar to Artisan \#1, Artisan \#2 didn't felt comfortable having to decide what and where to embroider. She insistently asked me for directions, thus we started working together to come up with some ideas.

Swimsuit \#3: Bikini flower embroidery. I was very involved in the embroidering of this swimsuit (Figure 8s and 9) because the artisan requested direction. We decided to pick an embroidery stitch from her work samples and then use it to embroider a flower in the bra and then repeat it in the bottom to coordinate both pieces. We established the shape, type of flower, and position to be embroidered. Afterwards, she finished the project with no issues, and the bikini looked very beautiful.

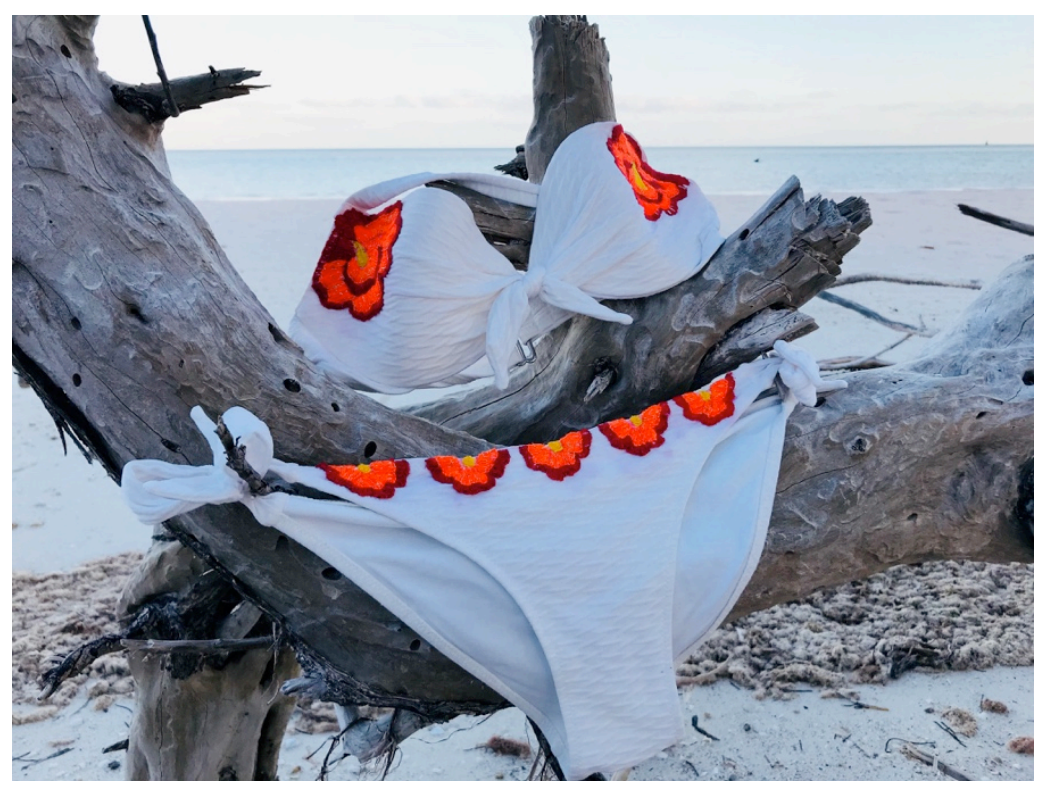

Figure 8. Bikini with flowers, embroidered by Artisan \#2. Photo by Hoshiakari Endo Portillo. 


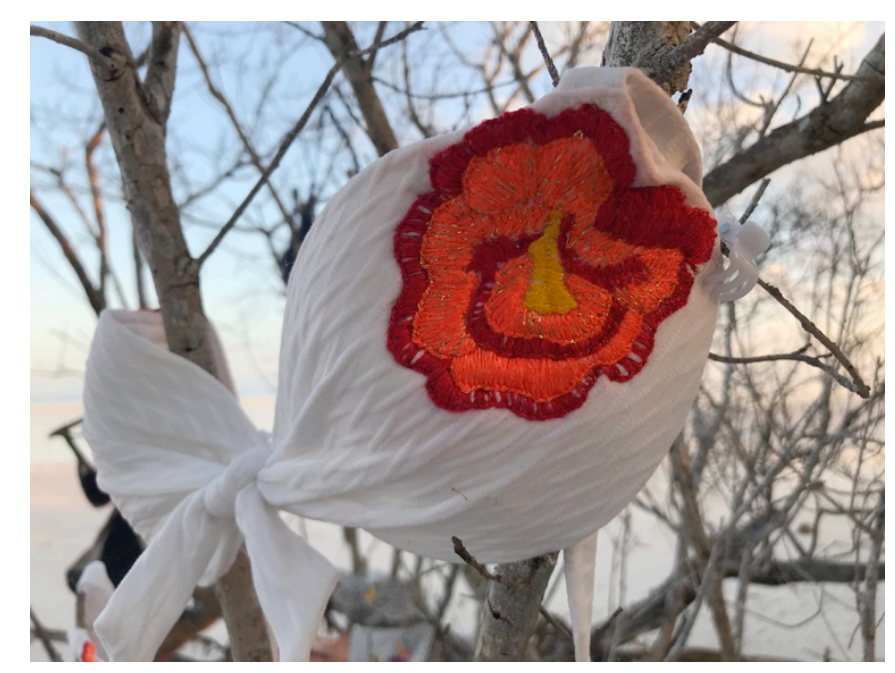

Figure 9. Flower detail embroidered by Artisan \#2. Photo by Hoshiakari Endo Portillo.

When I analyzed the swimsuit, I noticed she was confronted with one of the possible challenges I had mentioned before: embroidering over a pre-formed cup. I observed that the cup side she started with was completely pierced by the embroidery; on the contrary, the other cup was perfectly done without piercing the pre-formed cup. It is clear that while embroidering she realized that it would be better to embroider the bra without piercing the pre-formed cup. Thus, she intuitively corrected herself on the other cup. Regarding the colours, she chose yellow/orange and red because she thought they are beautiful colours.

Swimsuit \#4: Black monokini. As with swimsuit \#3, Artisan \#2 needed help to decide what and where to embroider. The monokini shape and fabric were not easy to approach either: the fabric was very silky and thin and the shape did not leave many free places to embellish. Therefore, we decided that the best course of action would be to embroider the trimmings. Due to the trim's width, it had to be a thin embroidery. Thus I showed her some linear designs in a simple cross-stitch technique. Two to three months passed before I could talk to her again, and by the time I contacted her, she had lost the motif we had chosen together and she had proceeded with another motif that her son helped her to find. I was pleased to see that she did not stop her 
work and instead made a decision about what to embroider. She chose a boxy pattern and embroidered it all along the monokini trimmings in different colours (Figures 10 and 11).

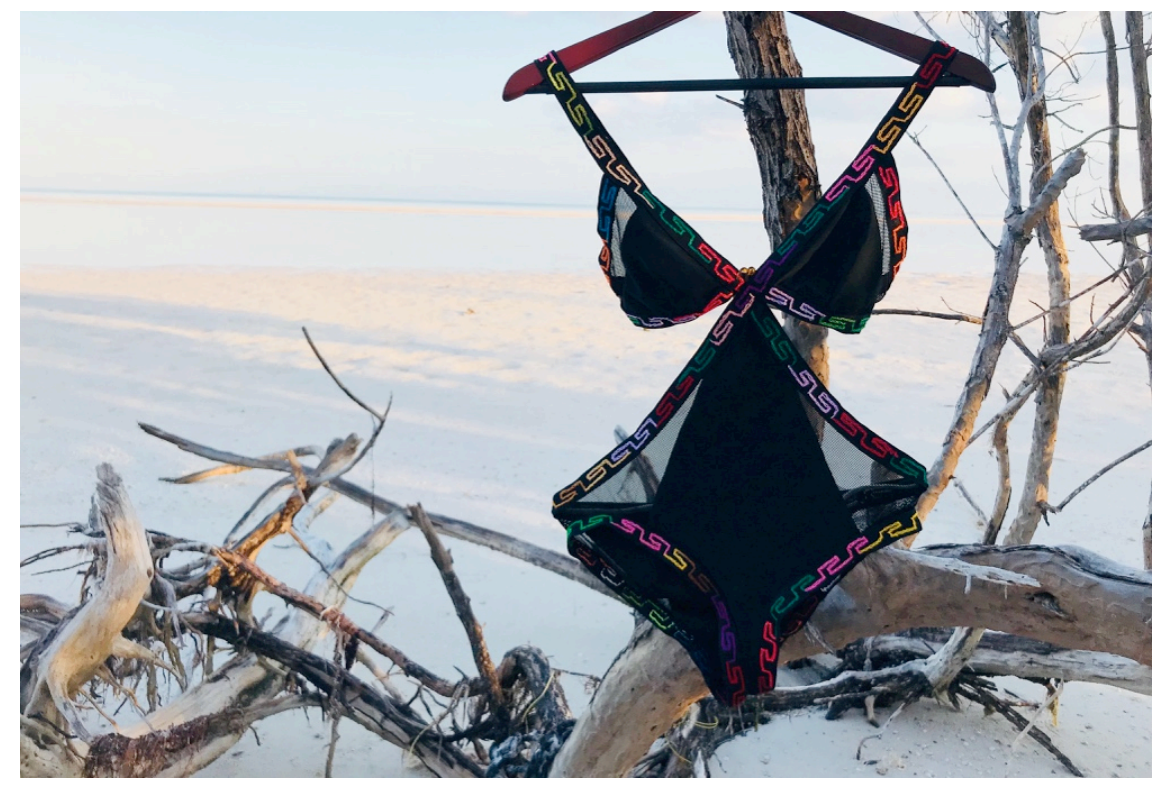

Figure 10. Monikini embroidered by Artisan \#2. It was embroidered only in the trimmings. Photo by Hoshiakari Endo Portillo.

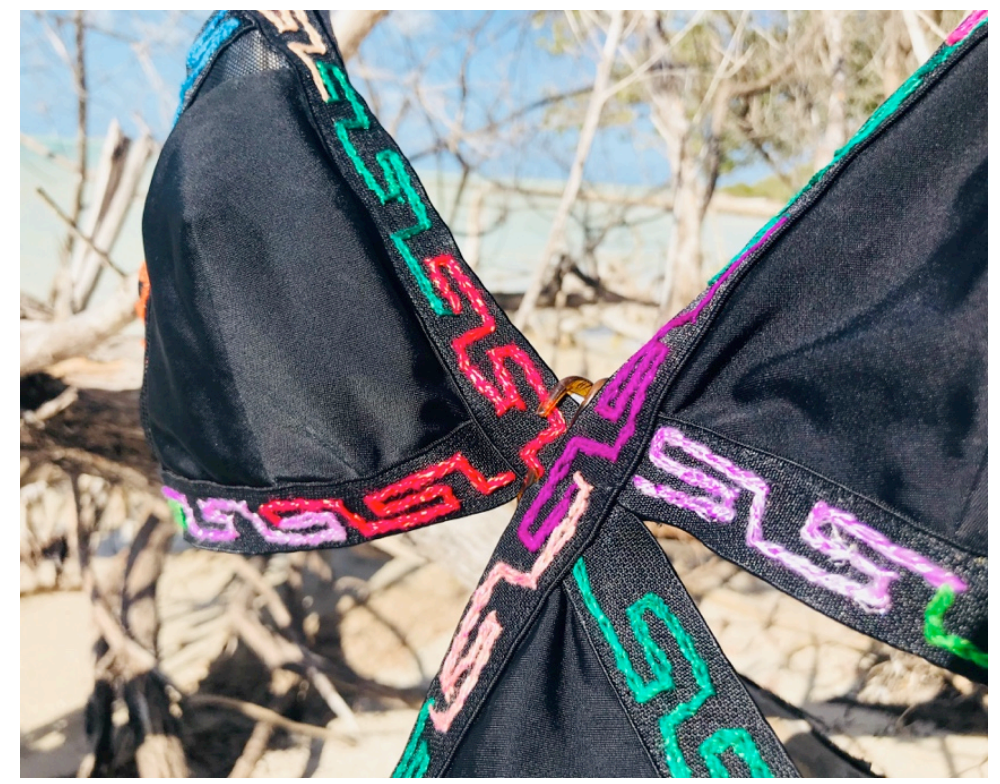

Figure 11. Detail of monokini embroidery in the trimmings. Boxy/chain pattern. Photo by Hoshiakari Endo Portillo. 
Swimsuit \#5: One-piece suit with scallops. I decided to give Artisan \#2 another

swimsuit to embroider (Figure 12), and gave her almost no direction except to execute a linear motif of sorts. Therefore, she took that literally and started embroidering horizontal lines across the swimsuit. Due to the fabric's elasticity, she started to have problems because she could not control the fabric to be able to embroider evenly. Luckily I was able to see her midway. While discussing the different possibilities, the artisan showed me more examples of her work, so once again we decided to take the edges of some napkins she had embroidered and put that kind of embroidery instead of the lines. Those edges were crocheted scallops that allow the fabric to stretch because of being added to strategic points of the garment that give them the necessary mobility to stretch (Figure 13).

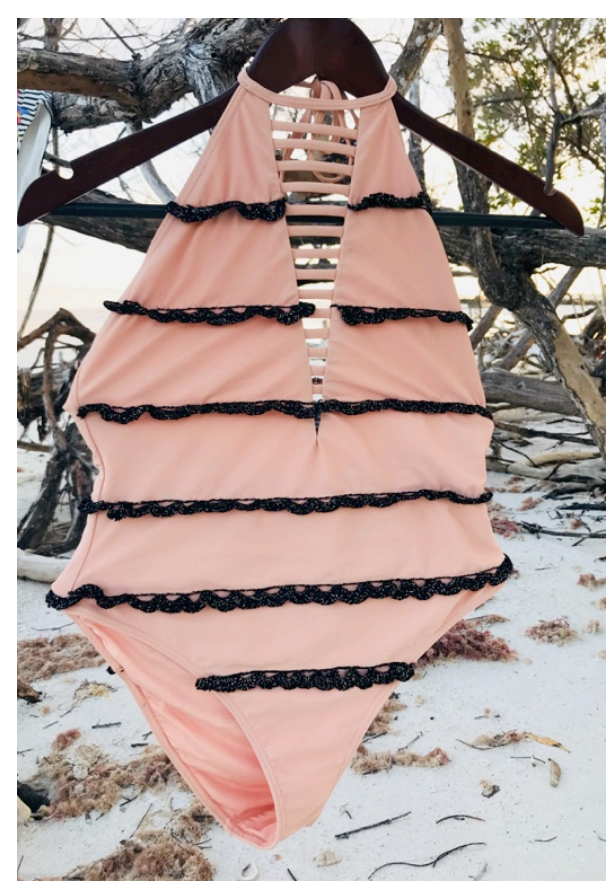

Figure 12. One-piece suit embroidered with crocheted scallops, made by Artisan \#2. Photo by Hoshiakari Endo Portillo. 


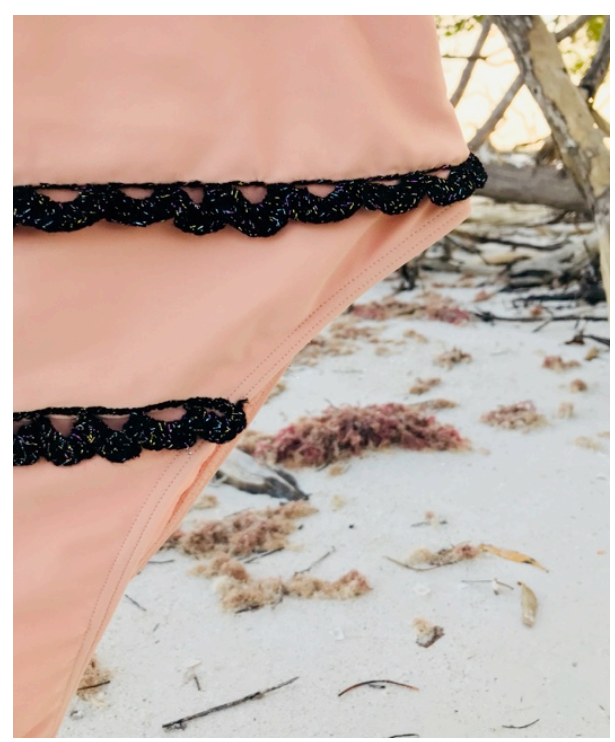

Figure 13. Detail of the embroidery. Photo by Hoshiakari Endo Portillo.

Cover-up "cáscara de tomate" stitch. This garment realization was tricky at the beginning, however it turned out beautifully executed (Figure 14). When I bought this piece, I was hesitant about the garment being viable for the project. The fabric of the garment was industrially embroidered already (Figure 15). I was concerned about over-embellishing it. Moreover, there was no place to embroider because the empty spaces of the fabric were transparent. Nevertheless, I presented the garment to Artisan \#2, and we both agreed on adding something colourful to it. We also decided that the best option was to embroider the centre of each of the geometrical figures that made up the original machine-embroidered motif. Like before, she embroidered the garment beautifully.

She came up with embroidering it with what she called "cáscara de tomate" stitch (Figure 16), which consists on passing the thread in a centre point every time. The colours she chose gave a new life to this garment in an intervention kind of way. It is important to point out that she left no sign of loose threads in the back of the garment, and she mentioned that she did this in case someone wanted to use this garment inside out. 


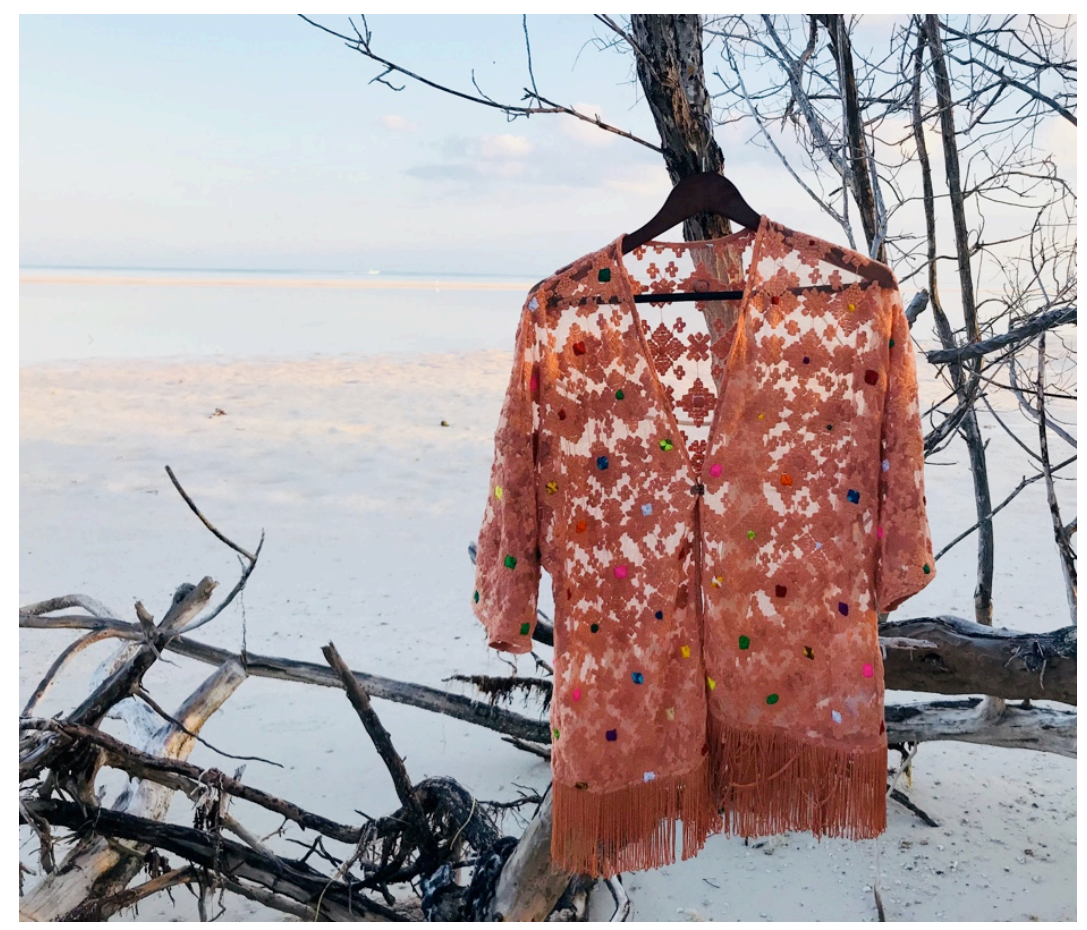

Figure 14. Cover-up made by Artisan \#2 with the stitch “cáscara de tomate." Photo by Hoshiakari Endo Portillo.

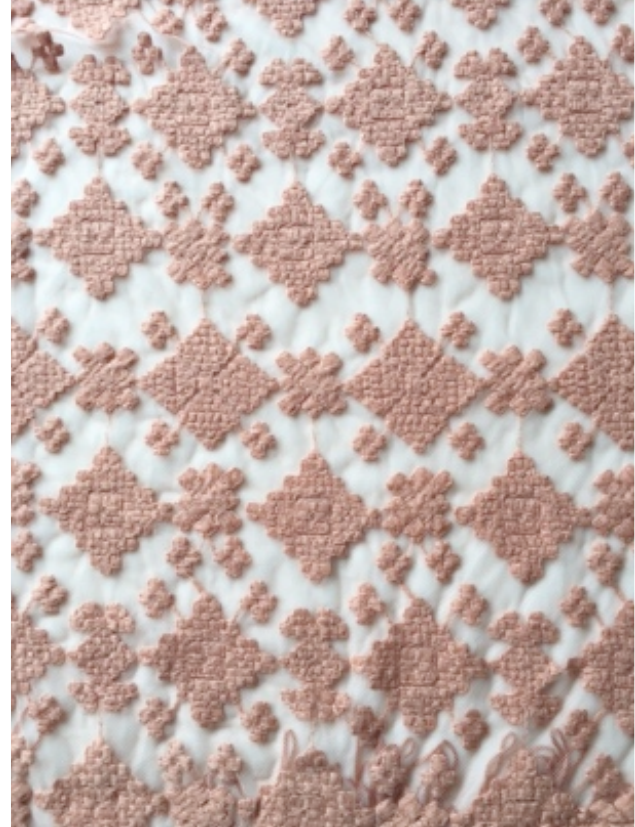

Figure 15. Cover-up fabric before being embroidered by Artisan \#2. Photo by Hoshiakari Endo Portillo.

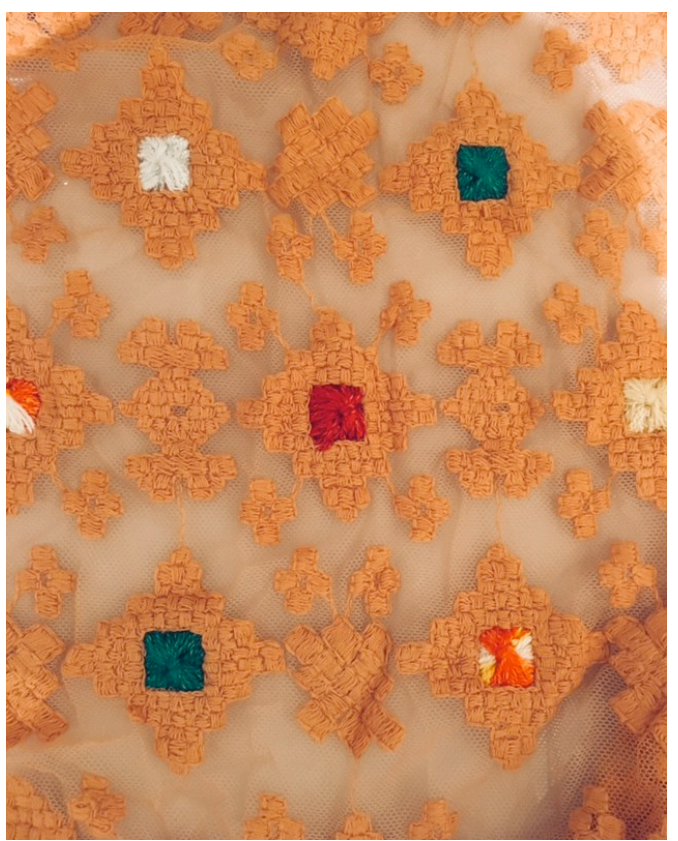

Figure 16. "Cáscara de tomate" stitch. Photo by Hoshiakari Endo Portillo. 
Regarding the pricing of Artisan \#2's work, I encountered some difficulties. Given the fact that we had several meetings, we developed a friendship. Thus, because of our friendship, she lowered the price of her work considerably. I tried to explain to her the importance of receiving a fair price, to which she answered that she understood and that she would do that from now on with other clients, but with me she would not because she enjoyed herself collaborating with me. She expressed that she would feel terrible if I paid her more.

The swimwear collection was done mostly to document the processes of creation, and considerations for the garment's actual functional use as a swimsuit to go in the water was not part of the creation. However, I would argue that for further development of this particular technique of creating a swimwear line out of existing ready-to-wear swimsuits embroidered by Mexican artisans, I would have provided the artisans with yarns that hold their colour and are resistant to chlorine. For the purposes of this project, I left thread choice open to the artisan to determine the typical range of materials with which they usually work.

\section{Editorial Photoshoot}

In order to commercialize the swimwear collection, I decided to integrate an editorial photoshoot. In collaboration with a photographer, we created a series of photos to publicize the swimsuits (see Appendix B for editorial photos). We experimented with close-ups and full shots (Figure 17). I considered it important to have close-ups in order to show details of the embroideries as they are a very important part of the swimwear collection (Figure 18). The main idea was to have a very modern and neutral surrounding to have the garments contrast the environment. 


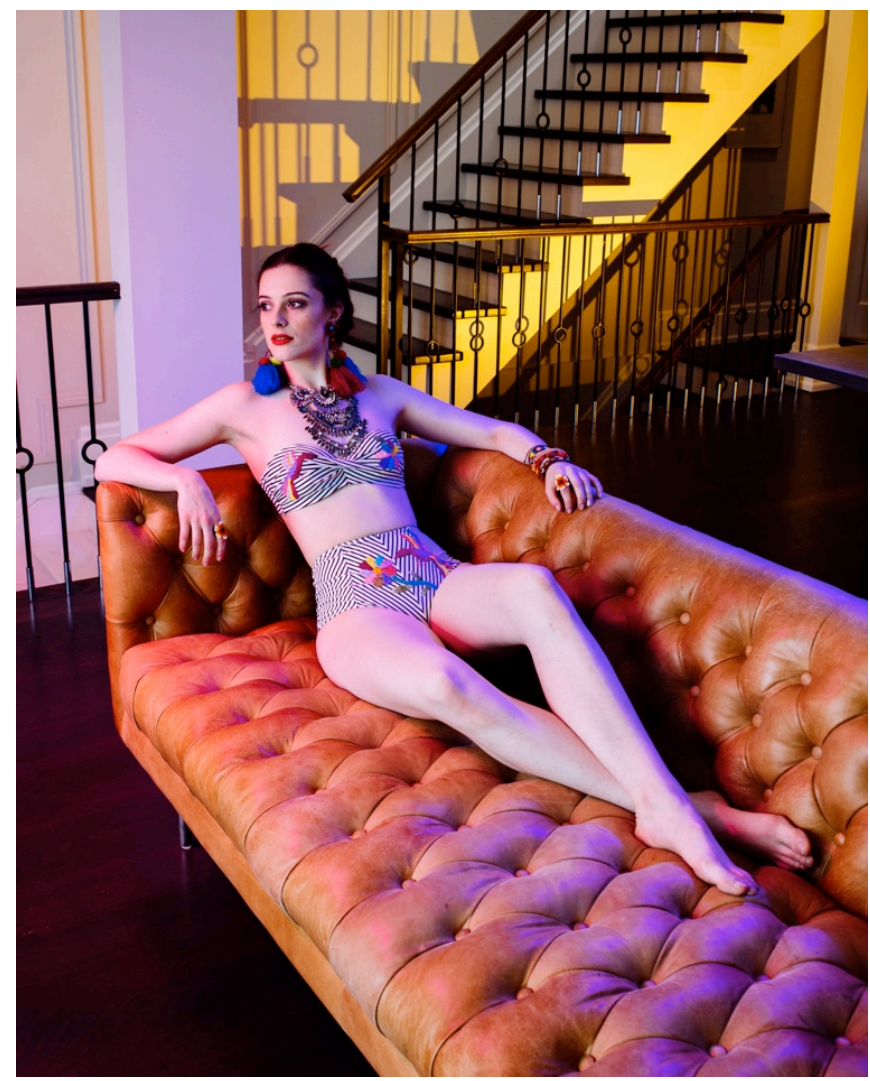

Figure 17. Full shot swimwear collection; bikini with Tenango-style embroidery by Artisan \#1. Photo by Justin Lee.

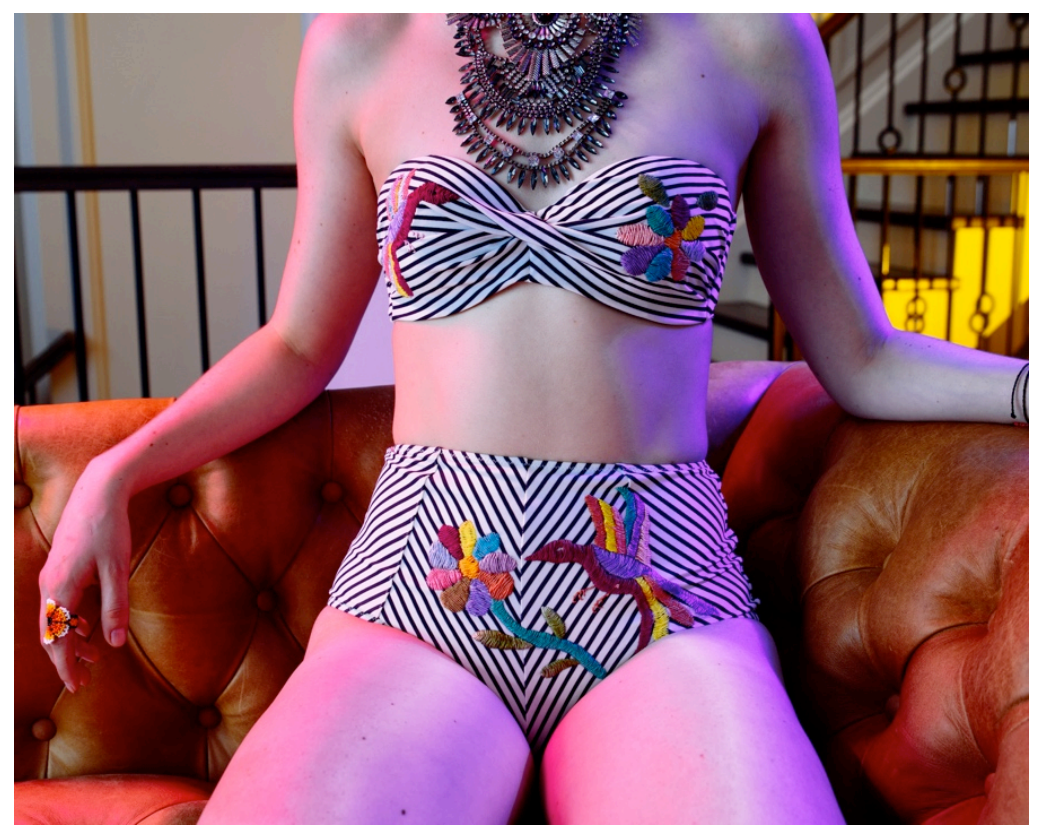

Figure 18. Close-up of the bikini embroidered like a Tenango made by Artisan \#1. Photo by Justin Lee. 


\section{Discussion}

The goal of this research was (a) to investigate the impact of commercializing indigenous Mexican arts and crafts and (b) to determine the best practices or strategies to collaborate with indigenous Mexican artisans. Therefore, I first analyzed the kind of crafts suitable to create a swimwear collection in collaboration with Mexican artisans (phase 1). Second, I conducted an interview with a designer who works collaboratively with Mexican artisans (phase 2), and I then conducted interviews with two Mexican artisans (phase 3). Lastly, I created a swimwear collection (phase 4) in collaboration with the two artisans I interviewed. The data derived from the four phases provided me with important information to answer the research questions: What would be the effects of indigenous Mexicans participating in the global fashion marketplace? Which are the best practices or strategies that would foster collaboration with indigenous Mexican craftspeople in an ethical and respectful way?

Smith (2012) argues that indigenous people's traditional knowledge can be introduced successfully into the marketplace; however, she also points out how "selling that legacy is viewed by many activist as tantamount to destroying the culture" (p. 220). Based on my research, I learned that including Mexican indigenous people in the fashion marketplace and "selling their legacy" may help perpetuate crafts traditions and may improve indigenous Mexican communities' quality of life. There are different strategies to commercialize craft traditions; some might be beneficial but some may be detrimental. That is why I outlined further down the strategies to collaborate with Mexican artisans that are favourable to foster craft traditions in an ethical and respectful way.

To measure the impact of indigenous Mexicans participating in the fashion marketplace (first research question), I consider it important to know the indigenous Mexican situation now. Given the fact that Artisan \#1 is part of the Otomí community, I did some research and found very interesting information that reflected several points touched on during her interview. 
Scholars like Gallardo Arias (2012), D’Aubeterre Buznego and Rivermar Pérez (2014), and Lanks (1938) discuss the relative isolation of Otomí communities. This isolation has allowed Otomí members to continue practising their original traditions. However, globalization and technology have played an important role in the last 20 years: "The gradual arrival of roads, television and now the internet to those remote regions has increasingly forced textile traditions to be abandoned or transformed" (Lavín \& Messeguer, 2015, p. 78).

Moreover, Gallardo Arias (2012) explained how Otomí youth have been exposed to technologies like television and the Internet, causing a deep change in the way they behave and dress (p. 33). This problem surfaced in the interviews I conducted with the artisans. During the interviews with Artisan \#1 and the designer, I learned that in order to travel to bigger towns or to Mexico City, people had to walk on country paths for several hours to get to a bus station. Presently it is a little easier, because instead of walking they may take a new bus route or a taxi to get to or to leave their community; however, it would still take Artisan \#1 around 5 hours to cover approximately 170 kilometers corresponding to the distance between San Pablito and Mexico City. I was surprised as well to see how "texting" has become a preferred form of communication. This communication was indirect though, because in the case of the artisans I worked with, the way to contact them was through their children's WhatsApp ${ }^{7}$ subscriptions. The designer I interviewed also pointed out that WhatsApp is the way she communicates with the artisans she collaborates with. This fact reveals the speed of changes these communities are experiencing — especially given the fact that they have been isolated for hundreds of years. The gap from one generation to the next one is alarming. Gallardo Arias (2012) observes that Otomí

\footnotetext{
${ }^{7}$ WhatsApp is a free application for intelligent phones that allows users to send and receive instant text messages, photos, videos, and audio recordings. According to its website (https://whatsapp.com) this application is used by more than 1 billion people in over 180 different countries.
} 
youth, influenced by modernity, no longer want to follow their parents' path and they only seek to get out of their community (p. 33). The question remains: What will happen to Otomí original traditions including textile crafts?

Another important issue I found is that Artisan \#2's son uses the Internet to help his mom find motifs to embroider. Lavín and Messeguer (2015) argue that technology's influence has "initiated new mestizo traditions" (p. 33). This is a very interesting point: if Mexican artisans start embroidering different motifs, the traditional ones are at risk of disappearing. Conversely, if they apply their techniques and use their traditional shapes and motifs to embroider contemporary ready-to-wear garments or accessories, we may achieve this "new mestizo tradition" and thus maintain textile traditions in a different way. Either way, we cannot let Mexican indigenous artisans stop practising their crafts. As the designer pointed out, "If they stop doing it, it is lost."

Another example that highlights the importance of fostering textile practices emerged during the interview with Artisan \#2. She explained that in Atlacomulco (her hometown), she used to produce her own thread to weave or embroider, however when she moved with her husband to another town, she stopped producing her own thread and now she barely remembers how to do it. The town in which she is living now is closer to Mexico City, therefore she has access to a great variety of materials, thus making it is easier, faster, and cheaper to buy threads than making them.

There are evident differences between the two artisans with whom I worked; the growth and progressiveness that Artisan \#1 achieved by working in collaboration with a fashion designer is remarkable. First of all, Artisan \#1 had no technical problems with embroidering the swimsuits. As I mentioned before, she managed the challenges (working with a stretchy fabric, embroidering a pre-formed cup) successfully. Secondly, Artisan \#1 demonstrated self-confidence 
when she had to decide what and where to embroider. Finally, regarding the cost of the embroideries, Artisan \#1 knew exactly how much her work was worth.

Even though Artisan \#2's work had little details that could have been improved, overall her embroideries were beautiful. With appropriate guidance, Artisan \#2 could easily achieve Artisan \#1's sense of self-worth and confidence. I believe that for designers collaborating with Mexican artisans, it would be very important to teach them the value of their work and how to price it correctly, following the example of the designer I interviewed working with Artisan \#1. Fostering traditional textile practices in Mexico is a very complex task that involves different factors. It is a multi-angled process in which professional designers play a very important role. Based on this research, including its literature review, interviews conducted, and my experience working with two Mexican artisans and most important as a designer, it is clear there are some strategies to responsibly collaborate with indigenous Mexican groups and foster Mexican textile craft traditions. Moreover, these strategies answer the second research question: Which are the best practices or strategies that would foster collaboration with indigenous Mexican craft people in an ethical and respectful way?

I narrowed the strategies down to six points that I consider important to take into consideration when attempting to foster textile traditions by collaborating with Mexican artisans. The six strategies are outlined explained below.

\section{Strategies}

1. Support indigenous artisans to continue living in their hometowns. In order to preserve traditional textiles legacy, I found it is very important to encourage indigenous communities to stay in their towns and to avoiding immigration. Lavín and Messeguer (2015) agree that indigenous communities should stay in their birthplace to continue practising their crafts; additionally, they point out that staying in their communities "also enables the transfer of 
values and traditions" (p. 81), which is extremely important to perpetuate the practice of their traditional arts and crafts.

\section{Provide indigenous artisans with a source of employment linked to their}

traditional crafts. In order to avoid immigration and encourage indigenous artisans to stay in their communities, it is important to ensure their well-being inside the community. This can be achieved by providing them with the money inflow needed to cover their needs. "Local products inspire and challenge the community while at the same time creating jobs and making use of local resources" (Fletcher, 2014 p. 140). Working locally not only will help maintain Mexican textile traditions but will also create an alternative to fast-fashion practices that deplete natural resources and promote unethical labour. There are several governmental associations ${ }^{8}$ or private institutions ${ }^{9}$ that offer logistical, economical, technical, and training support. Nevertheless, as designers, we can contribute by collaborating with Mexican indigenous communities and sharing our knowledge with them.

Such collaboration will encourage indigenous artisans to continue practising their traditions in a new way. The designer I interviewed helps the artisans by training them in the following ways: (a) she teaches them how to handle different materials; (b) she helps them to organize themselves to create a cooperative system; and (c) afterwards they appoint a leader who manages the production and travels back and forth with the samples, supplies, or production goods. The designer creates work strategies for the artisan that they can follow when working with someone else.

${ }^{8}$ e.g., FONART: Fondo Nacional para el Fomento de las Artesanías (National Fund to Foster Arts and Crafts); IIDART: Impulso a la Inovación y Desarrollo Artesanal del Estado de Puebla (Puebla's Arts and Crafts Innovation and Development Booster).

${ }^{9}$ e.g., BANAMEX Fomento Cultural. 


\section{Teach indigenous artisans how to value their work and to set fair prices in a}

global marketplace. During the interview I conducted with the designer who works collaboratively with indigenous Mexican artisans, she pointed out that often times artisans don't know how to price their work. Moreover, while buying crafts at the markets, it is very easy to bargain the artisans to lower the prices (in tourist pamphlets, bargaining is even recommended to tourist so they get cheaper items). That's why it is important to educate the indigenous artisans to price their work fairly. The designer I interviewed created a system in which each embroiderer has to write down in a data sheet the time it takes to make each embroidery. Afterwards, based on an hourly fair price, the designer calculates the fair cost of their work. One can think this is such an obvious way to cost one's work, however indigenous communities are not money driven. They embroider and do other traditional crafts partially because they enjoy doing it. They do not consider it important to know how long it takes to create something. Whatever benefit they obtain from their work is irrelevant to them, because just by creating it they feel fulfilled.

\section{Educate the buyers of indigenous crafts about the importance of paying} indigenous artisans a fair price. A very good way to do so is by informing buyers about this traditional practice and the story behind the items. Gauntlett (2011) argued that sharing one's creativity with the world would connect people, therefore it would be important to increase the general information about traditional craft practices in the context of mercantile exchanges. Moreover, offering the buyer a deeper explanation of the desired item to create this "connection" (Gauntlett, 2011, p. 10) would make the buyer fully understand the cost of the crafts.

\section{Remunerate and credit the cultural and intellectual property of indigenous}

Mexican artisans. During my research, I came across some Mexican brands that use motifs 
from indigenous Mexican crafts to create items that are sold internationally. However, the Mexican artisans who created those motifs are not economically remunerated. For example, entrepreneurs take the motifs and colours of traditional textiles and print them instead, to create modern garments or accessories. Afterwards they commercialize their products as a representation of Latin American traditional cultures. Even though the origin of each motif is explained and given credit, these items are not produced by Mexican artisans but rather are industrially manufactured. Thus, Mexican crafts are being exposed internationally, allowing people to know more about indigenous Mexican textiles, and perhaps awakening the desire to buy one next time they travel to Mexico. However, this practice is not directly fostering the textile practices among indigenous Mexican artisans.

\section{Develop channels to commercialize indigenous artisans arts and crafts. Training}

artisans to apply their techniques and motifs to contemporary ready-to-wear clothing may make their traditional textiles more appealing for sale in the global marketplace. This in turn will provide reliable, long-term economic support, and consequently preserve their textile and craft traditions. First, I questioned myself about introducing new materials or transforming the traditional textiles to be more appealing to a wider audience. What would be the impact of such changes? Would the commercialization process lead to the dissolution of traditional textile practices? I promptly remember what the designer said during the interview: "if they stop doing [their craft], then it is lost." Therefore, it is better to preserve those traditions, slightly different, than completely losing them.

Moreover, regarding the shape and motifs of indigenous dresses, Hesterberg (2000) pointed out how some indigenous communities have preserved their traditional dress motifs despite globalization and technology, because the dress "acts as a form of self-representation to a 
degree that modern attire can never achieve" (p. 89). In order to continue their traditional practices, indigenous communities need to find ways to locally support themselves economically. Therefore, they would not be forced to migrate and change their traditions altogether. Lavín and Messeguer (2015) explained that indigenous artisans protect their motifs' significance by either not letting foreigners use them or by hiding the meaning of them. Therefore, their traditions are protected as long as their well-being is achieved within their communities. In this way, fostering the textile practices as an economic source can help to preserve their traditions even if they are slightly transformed.

We need to commercialize/commodify indigenous artisans' textiles to preserve them. By helping to commercialize traditional indigenous textiles, we are re-using, transforming, and changing the purposes, forms, and motifs of the textiles. Therefore, it is important to use their shapes and motifs respectfully. Based on the findings of this research and from a designer perspective, I came up with some guidelines to follow when working or collaborating with indigenous textile artisans:

- Use traditional techniques, shapes, and motifs as much as possible, rather than those sourced from the Internet.

- Apply traditional techniques, shapes, or motifs to new materials, or manipulate them to create contemporary garments or accessories.

- Respect sacred shapes and their meanings.

- Improve the quality of indigenous artisans' materials by educating them about modern materials and processes.

- Respect the time that each artisan may need to maintain the value of their crafts. 


\section{Conclusion}

Proving the feasibility of incorporating indigenous Mexican arts and crafts into the global fashion marketplace is one of the main benefits of this research. In doing so, participating indigenous Mexican craftspeople may be fairly remunerated. Moreover, their work is both recognized and valued. Such benefits can enhance their identity, well-being, sense of self-worth, and ultimately making them feel empowered. While Artisan \#1's crafts are being transformed and commercialized by the designer, Artisan \#1 has not only learned to value her work but also to price it fairly. Moreover, she has acquired skills to manipulate different materials and elevate the quality of her work.

Moreover, indigenous Mexican communities may further benefit from this research because it provides some viable strategies on how to commercialize their traditional craft without endangering their cultural identity or negatively impacting their traditional legacies. Hence, the guidelines established in this research can be followed by Mexican indigenous artisans to push forward their crafts into a contemporary marketplace without the fear of losing their authenticity. In addition, this study may be applied to other ethnic communities experiencing similar challenges as Mexican indigenous groups; for example, indigenous groups from other Latin American countries. Guatemala, Belize, or other South American countries have a great variety of craft traditions equally in danger of disappearing. Moreover, the indigenous communities situation in other South American countries is very similar to that in Mexico, which makes this study suitable for the goal of preserving or reinforcing the cultural legacies of such indigenous communities.

Designers or people interested in starting a business in collaboration with indigenous communities can find this research relevant in gaining an understanding on how to enable fairly beneficial arrangements for both parties. As the main objective of the research project is to empower indigenous communities through fostering the practice of traditional textile crafts, following the recommended guidelines stemming this study would see to it that indigenous 
groups are minimally impacted as part of a collaboration or contract work arrangement. In addition, findings from this research will help inform design practitioners about the procedures that perpetuate indigenous crafts and the practices that endanger them. Therefore, the designer and the indigenous community can figure out ways to work that does not diminish the character of traditional craft practices.

Moreover, the creative part of the project demonstrated that embroidering ready-made garments as was done in this research can be a viable process. Instead of embroidering parts of garments and then assembling them together, the garment can be completely finished and embroidered once finished, thus skipping a phase of the production process. In addition, the project points to the potential of giving second-hand garments a "second life" by embroidering them with indigenous motifs. Fashion trends used to have a specific direction, however nowadays there are so many trends and fashion directions that everything is in fashion. We have to take advantage of this situation and encourage locally sustainable practices that can be incorporated into the global fashion market.

Finally, researchers and academics may also use this research to further their knowledge about preserving and fostering indigenous arts and craft practices in general. This research delineates some practices that can foster craft traditions. Hence, researchers or academics may broaden or deepen my findings on indigenous textile crafts by integrating them into their own academic research.

\section{Limitations}

The only real limitation regarding this research was the recruitment of indigenous Mexican artisans. The artisans felt intimidated by the REB protocol and refused to participate immediately. The two artisans whom I was able to interview agreed to participate because they trusted someone who knew me, and therefore they trusted me. For a researcher wanting to pursue this kind of study, I recommend taking into consideration more time for recruitment in order to 
gain the artisans' trust by getting to know them. Once the trust is gained, the artisans will be open to hear the research purposes and eventually decide if they want to participate or not. Otherwise, it would be beneficial to approach someone to gain both access to the community and their trust through this person.

Coming back to Bruno Traven's tale, I consider it important to acknowledge the way indigenous Mexican artisans operate and to respect them. In his tale, Traven (1960) illustrated the inherently anti-capitalist cultural and creative philosophy of Mexican artisans. Lavín and Messeguer (2015) explained that indigenous communities "are governed by daylight. They rise when the rooster crows and they end their work when the darkness of night hits" (p. 80). This is an example of how different their perception of life and time is, and we have to be able to understand and value that. The reason why their crafts are unique and authentic is because they put a piece of their heart in them. When I see the finished swimwear collection, all I can think about are the hands that embroidered each piece, their faces, their smiles, their story, the experiences I lived while developing each garment. Even the smell of ocote ${ }^{10}$ wood imbued in some of the bikinis creates this "aura" that a mass produced garment would never have. All these feelings are what should be transmitted to the final user to create this connection and raise awareness of the importance of Mexican traditional crafts. Keeping traditions alive is a task that involves us all.

"Just as a building that is not kept in repair soon disintegrates, so traditions have to be worked at to be sustained. The continuity of tradition is due not to its passive inertia but to its active regeneration —in the task of carrying on" (Hallam \& Ingold, 2007, pp. 5-6)

\footnotetext{
${ }^{10}$ Ocote is a kind of pine native to Mexico and Central America. The ocote wood is used by some Mexican communities in order to make a fire and warm up their houses.
} 


\section{Appendix A}

Swimsuits Before Being Embroidered by the Artisans

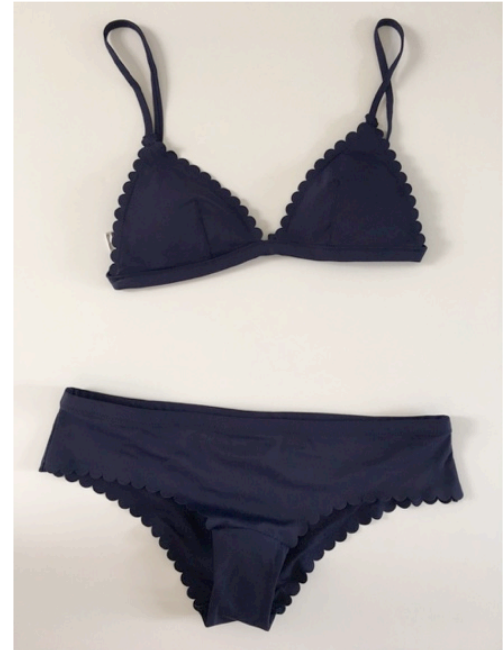

Swimsuit \#1

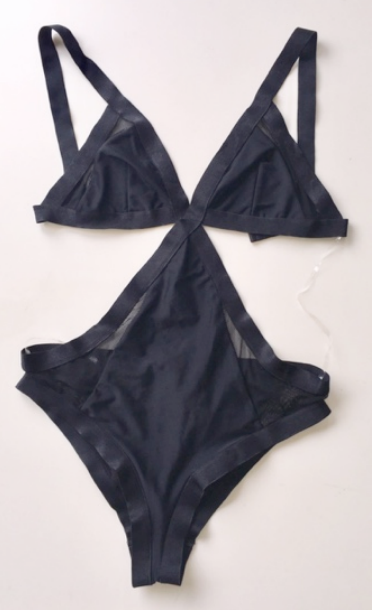

Swimsuit \#4

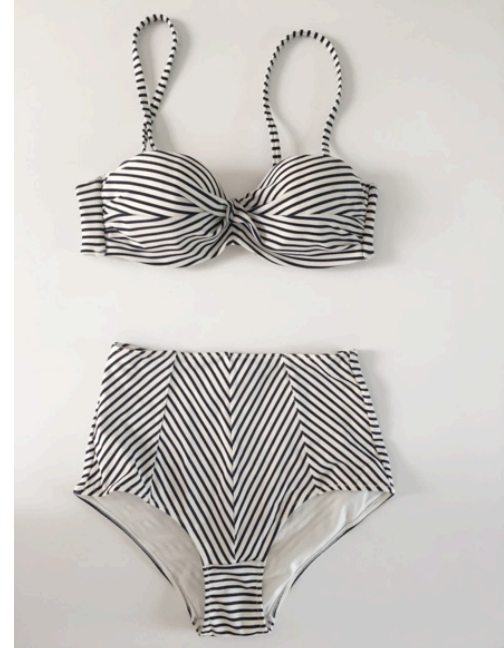

Swimsuit \#2

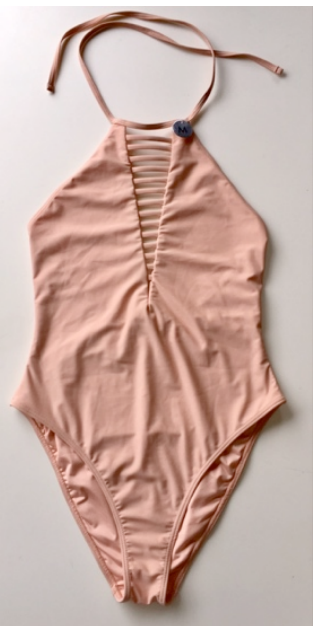

Swimsuit \#5

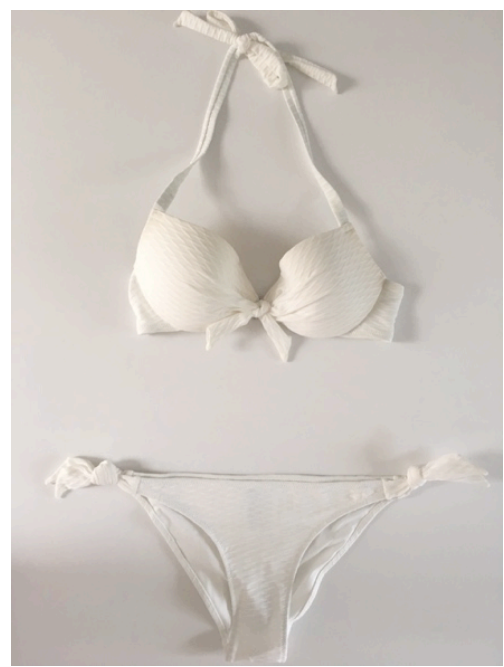

Swimsuit \#3

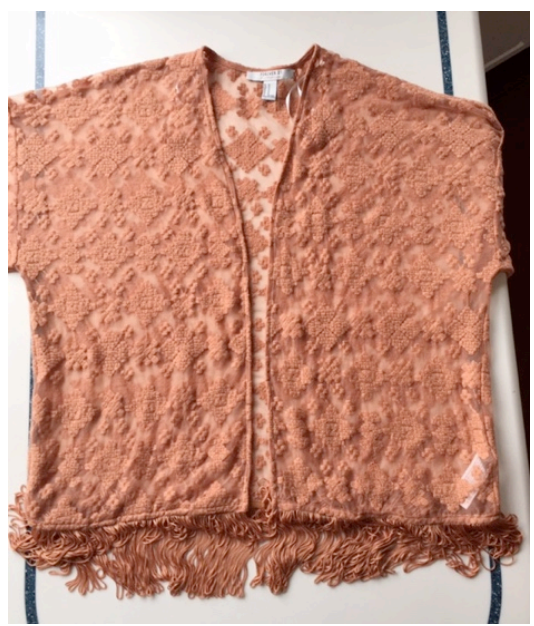

Cover-up 


\section{Appendix B}

Editorial Photoshoot of the Swimwear Collection
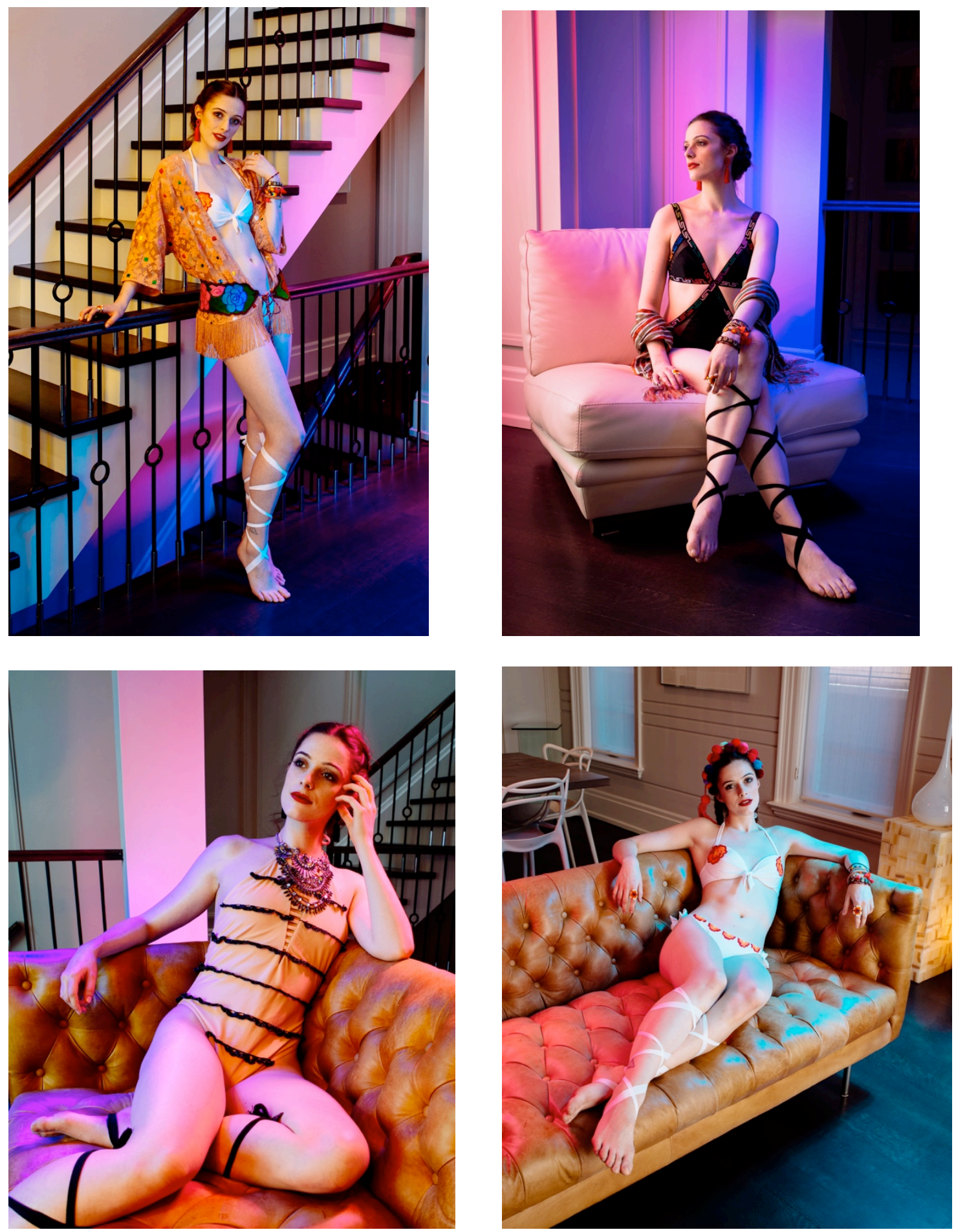

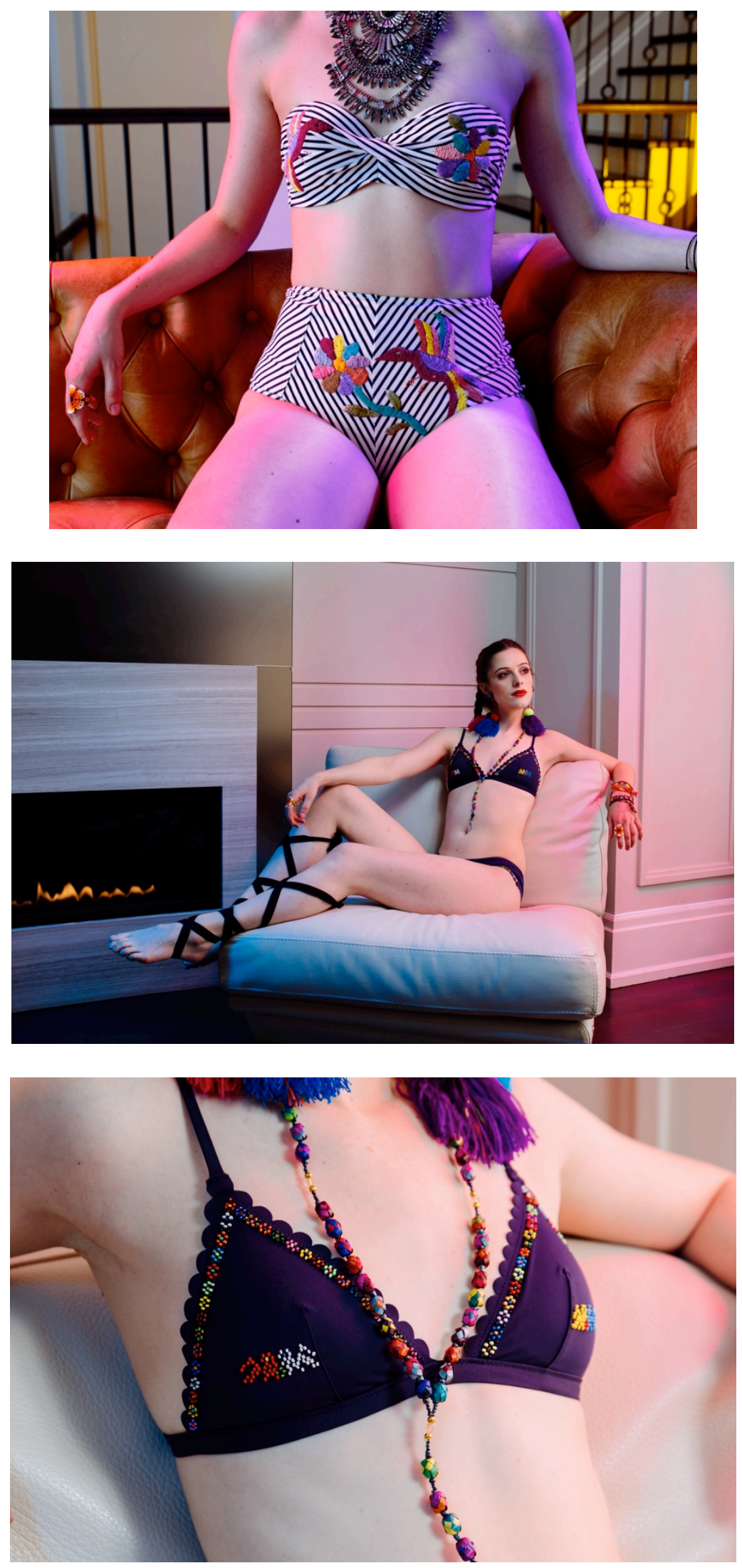


\section{References}

Alonso, A. M. (2004). Conforming disconformity: "Mestizaje," hybridity, and the aesthetics of Mexican nationalism. Cultural Anthropology, 19(4), 459-490.

doi:10.1525/can.2004.19.4.459

Artes de Mexico. (1996). Textiles de Oaxaca. Artes de Mexico (\#35). Mexico City, Mexico: Author.

Artes de Mexico. (2000). La Tehuana. Artes de Mexico (\#49). Mexico City, Mexico: Author.

Artes de Mexico. (2011). Textiles Mazahuas. Artes de Mexico (\#102). Mexico City, Mexico: Author.

Benjamin, W. (2005). The work of art in the age of mechanical reproduction. Marxist Internet Archive. (Original work published 1936). Retrieved from https://www.marxists.org/reference/subject/philosophy/works/ge/benjamin.htm

Berger, R. (2015). Now I see it, now I don't: Researcher's position and reflexivity in qualitative research. Qualitative Research, 15(2), 219-234. doi:10.1177/1468794112468475

Cardenas, D. A. (2016, April 23). ¿Con los Tenangos, un comercio justo? Milenio. Retrieved from http://www.milenio.com/firmas/david_aaron_cardenas/Tenangos-comerciojusto_18_724907531.html

Creswell, J. W. (2003). Research design: Qualitative, Quantitative and Mixed Methods approaches (2nd ed.). Thousand Oaks, CA: Sage.

D’Aubeterre Buznego, M. E., \& Rivermar Pérez, M. L. (2014). From amate paper making to global work: Otomí migration from puebla to north carolina. Latin American Perspectives, 41(3), 118-136. doi:10.1177/0094582X13519426

De Orellana, M. (1996). Hilos que son palabras. Artes de Mexico, 35(7), 7-8. 
Dissanayake, D. G. K., Perera, S., \& Wanniarachchi, T. (2017). Sustainable and ethical manufacturing: A case study from handloom industry. Textiles and Clothing Sustainability, 3(1) 1-10. http://doi.org/10.1186/s40689-016-0024-3

Dragusanu, R., Giovannucci, D., \& Nunn, N. (2014). The economics of fair trade. The Journal of Economic Perspectives Journal of Economic Perspectives, 28(3), 217-236. doi:10.1257/jep.28.3.217

Fletcher, K. (2007). Slow fashion. The Ecologist, 37(5), 61.

Fletcher, K. (2010). Slow fashion: An invitation for systems change. Fashion Practice: The Journal of Design Creative Process \& the Fashion Industry, 2(2), 259-266. http://doi.org/10.2752/175693810X12774625387594

Fletcher, K. (2014). Sustainable fashion and textiles: Design journeys (2nd ed.). New York, NY: Routledge.

Foley, J. (1997, July). The dimensions of empowerment. Paper presented at the annual international conference of the Community Development Society, Athens, GA. Retrieved from https://files.eric.ed.gov/fulltext/ED413514.pdf

Gallardo Arias, P. (2012). La sierra de Tutotepec. In Ritual, palabra y cosmos otomí: Yo soy costumbre, yo soy de antigua (pp. 21-38). Mexico City, Mexico: UNAM Instituto de Investigaciones Históricas. Retrieved from http://www.historicas.unam.mx/publicaciones/publicadigital/libros/ritualpalabra/RPC003.pdf

Garcia, E., \& Vinebaum, L. (2016). The Museo Textil de Oaxaca: “A live space for the textile arts": Interview with Ana Paula Fuentes. Textile, 14(1), 122-135. http://doi.org/10.1080/14759756.2016.1142787

Gauntlett, D. (2011). Making is connecting: The social meaning of creativity, from DIY and knitting to YouTube and Web 2.0. Cambridge, UK: Polity Press. 
Gobierno del Estado de México. (2018). Nahua. Retrieved from http://www.edomex.gob.mx/nahua

Hallam, E., \& Ingold, T. (2007). Creativity and cultural improvisation. Oxford, UK: Berg.

Ham, M., Mrcela, D., \& Horvat, M. (2016). Insights for measuring environmental awareness. Ekonomski Vjesnik, 29(1), 159-176.

Hesterberg, A. (2000). Una segunda piel. Artes de México, 49, 88-89.

Huck, C. (2012). Special section on cultural appropriation introduction: Mobility, transfers, and cultural appropriation. @BULLET Transfers, 2(3), 76-80. http://doi.org/10.3167/trans.2012.020305

Ibarra, R. L., \& Strawn, S. M. (2015). "Make friends with Mexico”: The Mexican tourist jacket. Fashion, Style \& Popular Culture, 3(1), 7-20. http://doi.org/10.1386/fspc.3.1.7_1

Jung, S., \& Jin, B. (2016a). From quantity to quality: Understanding slow fashion consumers for sustainability and consumer education. International Journal of Consumer Studies, 40(4), 410-421. http://doi.org/10.1111/ijcs.12276

Jung, S., \& Jin, B. (2016b). Sustainable development of slow fashion businesses: Customer value approach. Sustainability, 8(6), 540. http://doi.org/10.3390/su8060540

Lanks, H. C. (1938). Otomi indians of Mezquital Valley, Hidalgo. Economic Geography, 14(2), 184-194. doi:10.2307/141670

Lavín, L., \& Messeguer, M. (2015). Fashion design and fashion cooperatives: A case study of the Lydia Lavín brand. In A. Gwilt (Ed.), Fashion design for living (pp. 78-93). New York, NY: Routledge.

Lechuga , R. (1996). Mirando los textiles Oaxaqueños. Artes de Mexico, 35(7), 11-23.

Levander, U. (2010). Social enterprise: Implications of emerging institutionalized constructions. Journal of Social Entrepreneurship, 1(2), 213-230. http://doi.org/10.1080/19420676.2010.511815 
Luckman, S. (2013). The aura of the analogue in a digital age: Women's crafts, creative markets and home-based labour after Etsy. Cultural Studies Review, 19(1), 249-270. http://dx.doi.org/10.5130/csr.v19i1.2585

Maguirre, M. V., Ruelas, G. C., \& Torre, C. G. D. LA. (2016). Women empowerment through social innovation in indigenous social enterprises. RAM. Revista de Administração Mackenzie, 17(6), 164-190. http://doi.org/10.1590/167869712016/administracao.v17n6p164-190

Marks, D. (2015). Molas: Displaying the quotidian before Andy Warhol. Fashion, Style \& Popular Culture, 3(1), 35-50. doi:10.1386/fspc.3.1.35_1

Martinez-Eschazabal, L. (1998). Mestizaje and the discourse of national/cultural identity in Latin America, 1845-1959. Latin American Perspectives, 25(3), 21-42.

Mazariegos, O. C. (2010). Of birds and insects: The hummingbird myth in ancient Mesoamerica. Ancient Mesoamerica, 21(1), 45-61. doi:10.1017/S0956536110000155

Moore, M., \& Prain, L. (2009). Yarn bombing: The art of crochet and knit graffiti. Vancouver, BC: Arsenal Pulp Press.

Moxley, D. P. (2013). Incorporating art-making into the cultural practice of social work. Journal of Ethnic \& Cultural Diversity in Social Work, 22(3-4), 235-255. doi:10.1080/15313204.2013.843136

Navarro, H. (2014). Fashion as public art: Strengthening communities through site-specific fashion collections. Fashion, Style \& Popular Culture, 1(3), 445-457. http://doi.org/10.1386/fspc.1.3.445_1

Ozdamar Ertekin, Z., \& Atik, D. (2015). Sustainable markets: Motivating factors, barriers, and remedies for mobilization of slow fashion. Journal of Macromarketing, 35(1), 53-69. doi:10.1177/0276146714535932 
Pham, M.-H. T. (2016). Feeling appropriately. Social Text, 34(3 128), 51-74. http://doi.org/10.1215/01642472-3607576

Pookulangara, S., \& Shephard, A. (2013). Slow fashion movement: Understanding consumer perceptions An exploratory study. Journal of Retailing and Consumer Services, 20(2), 200-206. doi:10.1016/j.jretconser.2012.12.002

Powell, B., \& Zwolinski, M. (2012). The ethical and economic case against sweatshop labor: A critical assessment. Journal of Business Ethics, 107(4), 449-472. http://doi.org/10.1007/s10551-011-1058-8

Reisch, M., \& Jani, J. S. (2012). The new politics of social work practice: Understanding context to promote change. The British Journal of Social Work, 42(6), 1132-1150. doi:10.1093/bjsw/bcs072

Shand, P. (2002). Scenes from the colonial catwalk: Cultural appropriation, intellectual property rights, and fashion. Cultural Analysis, 3, 47-88.

Smith, L. T. (2012). Decolonizing methodologies: Research and indigenous peoples (2nd ed.) London, UK: Zed Books.

Stephen, L. (1987). Zapotec weavers of Oaxaca: Development and community control. Cultural Survival Quarterly, 11(1), 46-48.

Stephens, J., \& Tiwari, R. (2015). Symbolic estates: Community identity and empowerment through heritage. International Journal of Heritage Studies, 21(1), 99-114. http://doi.org/10.1080/13527258.2014.914964

Traven, B. (1960). Canasta de cuentos Mexicanos. Mexico City, Mexico: Selector. Waterhouse, J., \& Levine, F. (2010). Indie craft. London, UK: Laurence King. Wilson, E. (2003). Adorned in dreams: Fashion and modernity. London, UK: I.B. Tauris. 
Wilson, W. A. (2004). Indigenous knowledge recovery is indigenous empowerment. American Indian Quarterly, 28(3), 359-372.

Wood, W. W. (2000). Stories from the field, handicraft production, and Mexican national patrimony: A lesson in translocality from B. Traven. Ethnology, 39(3), 183-203. 